Research Paper

\title{
Overcoming imatinib resistance conferred by the BIM deletion polymorphism in chronic myeloid leukemia with splice-switching antisense oligonucleotides
}

\author{
Jun Liu' ${ }^{1, *}$, Malini Bhadra ${ }^{1, *}$, Joanna Rajeswary Sinnakannu ${ }^{2}$, Wan Lin Yue ${ }^{1,3}$, Cheryl \\ Weiqi Tan ${ }^{1}$, Frank Rigo ${ }^{4}$, S. Tiong Ong ${ }^{2,5,6,7}$ and Xavier Roca ${ }^{1}$ \\ ${ }^{1}$ School of Biological Sciences, Nanyang Technological University, Singapore \\ ${ }^{2}$ Cancer and Stem Cell Biology Signature Research Programme, Duke-NUS Medical School, Singapore \\ ${ }^{3} \mathrm{CN}$ Yang Scholars Programme, Nanyang Technological University, Singapore \\ ${ }^{4}$ Ionis Pharmaceuticals, Carlsbad, California, USA \\ ${ }^{5}$ Department of Haematology, Singapore General Hospital, Singapore \\ ${ }^{6}$ Department of Medical Oncology, National Cancer Centre Singapore, Singapore \\ ${ }^{7}$ Department of Medicine, Duke University Medical Center, Durham, North Carolina, USA \\ * Co-first authors \\ Correspondence to: Xavier Roca, email: xroca@ntu.edu.sg \\ S. Tiong Ong, email: sintiong.ong@duke-nus.edu.sg \\ Keywords: alternative splicing, BIM, chronic myeloid leukemia, imatinib, antisense oligonucleotides \\ Received: December 15, $2016 \quad$ Accepted: July 25, $2017 \quad$ Published: September 06, 2017 \\ Copyright: Liu et al. This is an open-access article distributed under the terms of the Creative Commons Attribution License 3.0 \\ (CC BY 3.0), which permits unrestricted use, distribution, and reproduction in any medium, provided the original author and source \\ are credited.
}

\section{ABSTRACT}

Many tyrosine kinase-driven cancers, including chronic myeloid leukemia (CML), are characterized by high response rates to specific tyrosine kinase inhibitors (TKIs) like imatinib. In East Asians, primary imatinib resistance is caused by a deletion polymorphism in Intron 2 of the BIM gene, whose product is required for TKI-induced apoptosis. The deletion biases BIM splicing from exon 4 to exon 3, generating splice isoforms lacking the exon 4-encoded pro-apoptotic BH3 domain, which impairs the ability of TKIs to induce apoptosis. We sought to identify splice-switching antisense oligonucleotides (ASOs) that block exon 3 but enhance exon 4 splicing, and thereby resensitize BIM deletion-containing cancers to imatinib. First, we mapped multiple cis-acting splicing elements around BIM exon 3 by minigene mutations, and found an exonic splicing enhancer acting via SRSF1. Second, by a systematic ASO walk, we isolated ASOs that corrected the aberrant BIM splicing. Eight of 67 ASOs increased exon 4 levels in BIM deletion-containing cells, and restored imatinib-induced apoptosis and TKI sensitivity. This proof-of-principle study proves that resistant CML cells by $B I M$ deletion polymorphism can be resensitized to imatinib via splice-switching BIM ASOs. Future optimizations might yield a therapeutic ASO as precision-medicine adjuvant treatment for BIM-polymorphism-associated TKI-resistant CML and other cancers.

\section{INTRODUCTION}

Small-molecule targeting of mutant oncoproteins in human cancers has resulted in significant improvements in progression free survival (PFS) and overall survival (OS) compared to conventional chemotherapy [1-3]. In particular, inhibition of BCR-ABL1 by the tyrosine kinase inhibitor (TKI) imatinib (also known as Gleevec or Glivec) in patients with chronic myeloid leukemia 
(CML) has transformed a previously deadly disease into a chronic illness [4]. Similarly, other TKIs like erlotinib exhibit $>70 \%$ response rates in non-small cell lung cancer (NSCLC) patients with epidermal growth factor receptor (EGFR) activating mutations [5-7]. Other human cancers like c-KIT-driven gastrointestinal stromal tumours and BRAF-driven melanomas also have available TKIs. The BIM (BCL2-Interacting Mediator of cell death, also known as BCL2L11) protein is a $\mathrm{BH} 3$-only proapoptotic member of the BCL-2 family that is absolutely required for the cancer killing of such drugs via the intracellular or mitochondrial pathway, elicited via upregulation of its expression at different levels [8-14]. However, despite the high overall TKI response rates, significant heterogeneity in both the depth and duration of responses exists [15-17].

We previously discovered a common 2,903-base pair (bp) deletion polymorphism in the BIM gene that contributed to response heterogeneity in patients with CML and epidermal growth factor receptor-mutated nonsmall cell lung cancer (EGFR-NSCLC). The deletion allele is present in East Asians and Latin Americans with carrier frequency $13-16 \%$, and absent in Caucasians and Africans $[18,19]$. While the presence of the BIM deletion reduces the first-line response to imatinib in CML patients [19], in EGFR-NSCLC patients it predicts an inferior OS compared to individuals without the deletion (28.8 vs 40.2 months respectively, $\mathrm{p}<0.017$ ) [20]. Four independent groups from Taiwan, China, and Japan have replicated our findings [21-25], although two South Korean centres did not show any differences $[26,27]$, which may possibly be due to genetic differences between East Asians [28, 29].

BIM expression is largely regulated by alternative splicing, which generates three major proapoptotic isoforms named BIMEL (extralarge), BIML (large) and BIMS (small), and two isoforms that are not proapoptotic collectively named as BIM $\gamma$ (with BIM $\gamma 1$ and BIM $\gamma 2$ ) (Figure 1A). BIMEL, BIML and BIMS mRNAs all contain exon 4 (E4) while BIM $\gamma$ isoforms include exon 3 (E3) instead [19, 30]. Mechanistically, the deletion polymorphism biases alternative splicing away from E4 toward E3, resulting in decreased expression of E4containing isoforms, and increased E3/E4 ratio [19]. E3 and $\mathrm{E} 4$ cannot be included in the same spliced transcript because E3 lacks a 5' splice sites (5'ss) to be connected with the 3' splice sites (3'ss) of E4, but instead E3 is a terminal exon with its own canonical polyadenylation signal. Because only E4 encodes the pro-death $\mathrm{BH} 3$ domain of BIM, the patients with the deletion exhibit impaired ability to upregulate $\mathrm{BH} 3$-containing BIM protein isoforms by TKIs, thus resulting in intrinsic TKI resistance. We also found that the 2,903-bp polymorphic fragment contains multiple and redundant Intronic Splicing Silencers (ISSs), and that the last 322-nucleotide (nt) of this segment is sufficient to recapitulate the repressive effects on E3 by the whole fragment, with an important 23-nt ISS at its 3' end [31]. Previous studies also revealed that the trans-acting factor serine/arginine-rich splicing factor (SRSF1) promotes E3 inclusion [32], and that Polypyrimidine Tract Binding Protein 1 and hnRNP C repress it [31]. However, the binding sites of these factors in the BIM transcript remain to be identified, as well as additional activators and repressors of E3 inclusion. Furthermore, SRSF2 and SRSF6 were also shown to increase $B I M S$, which encodes the most potent of all proapoptotic splice isoforms [33, 34].

Beyond the splicing effects of the BIM deletion, alternative splicing is a commonly altered mechanism that can fuel tumorigenesis [35], and is also becoming a therapeutic target. Alternative splicing connects exons in different ways to generate different mRNAs from one primary transcript [36], and largely accounts for the complexity of the transcriptome and proteome in humans [37]. Each alternative splicing event is usually regulated by many cis-acting elements and their cognate transacting factors, as well as by RNA structure, transcription and chromatin. The essential cis-acting splicing elements include the 5'ss and 3'ss, as well as the branch point sequence (BPS) around the lariat adenosine [38]. In addition, exonic or intronic splicing enhancers (ESEs, ISEs) or silencers (ISEs, ISSs) either activate or repress splicing via binding to activators or repressors, such as serine/arginine-rich (SR) proteins and heterogeneous nuclear ribonucleoproteins (hnRNPs) [39]. Splicing is catalyzed by the spliceosome, which is a large and dynamic macromolecule composed of five small nuclear ribonucleoproteins as well as individual polypeptides which assemble on the pre-mRNA in a stepwise manner [40]. A recent structure of yeast catalytic spliceosome $[41,42]$ has provided significant insights into basic splicing mechanisms but less so into regulation, because the alternative splicing patterns are usually established prior to formation of this complex. Furthermore, as the alternative splicing prediction tools are still inaccurate, elucidation of the regulatory mechanisms for individual splicing events still needs focused studies as the one presented here.

Given the importance of physiologic splicing in regulating growth, survival, and differentiation [36] it is therefore unsurprising that both mutations at cis-acting elements as well as mutations or expression alterations of trans-acting splicing factors contribute to cancer [35], such as the case of SRSF1 as a potent oncogene in certain tumors $[32,43,44]$. The discovery of frequent mutations in splicing factors associated to myelodysplastic syndromes (MDS) [45] illustrates that splicing plays an important role in myeloid cells, and that their defects can result in pre-malignant syndromes. The most frequently mutated splicing factor in MDS, splicing factor 3 subunit B1, is also the target of antitumor drugs such as spliceostatin A [46]. In addition to somatic mutations, a few known germline polymorphisms can change the splicing patterns and modify the protein's function [47, 48]. Important 
A
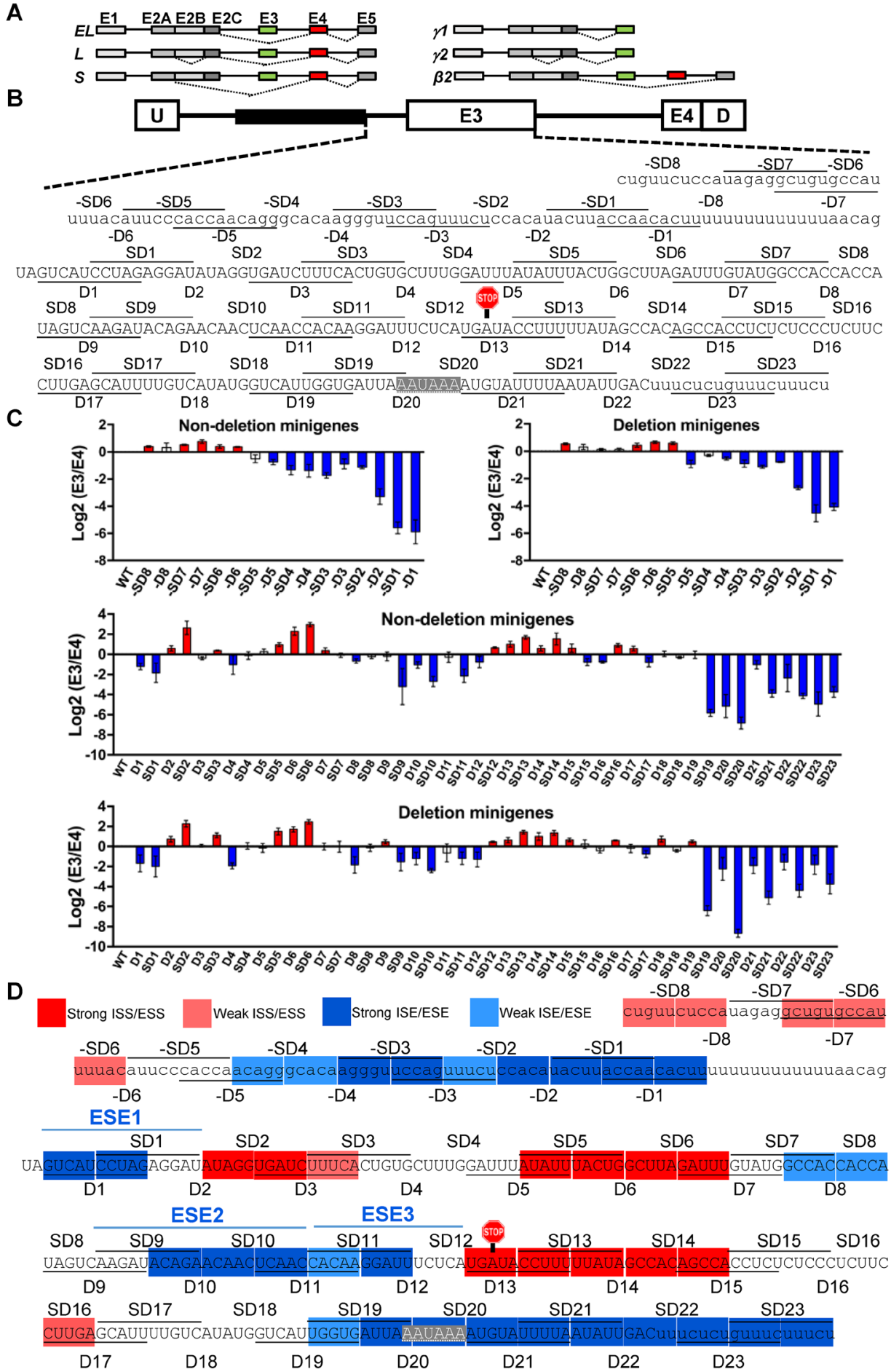

Figure 1: Deletion scan of BIM E3 and upstream intronic region reveals many splicing enhancers and silencers. (A) Schematic of the major proapoptotic (left) and non-apoptotic (right) BIM isoforms. Exons are indicated on top of boxes, introns are depicted as lines, and splicing patterns as thin dashed lines. BIM $\beta 2$ is a minor nonapoptotic isoform encoded by an mRNA lacking both E3 and E4. (B) Design of the BIM minigene with boxes as exons and lines as introns. U and D are adenoviral exons, and the 2,903-bp polymorphic fragment is shown as black box. The 10-nt deletions and staggered deletions ( $\mathrm{D}$ and SD series) are consecutively indicated as lines and spaces within the sequences. The E3 stop codon (UGA) and polyadenylation signal (AAUAAA) are highlighted. (C) Log2(E3/ E4) ratios by real-time RT-PCR for the D and SD series in $\Delta 10$ (nondeletion minigenes) or $\Delta 11$ (deletion minigenes), with red and blue indicating silencers and enhancers, respectively, with a P $<0.05$ compared to WT minigene using Student's t-test. (D) Color-coded map of ESEs, ISEs, ESSs and ISSs within and upstream E3. Strong and weak are respectively defined by $\geq 50$ or $\geq 30 \%$ splicing change by the deletion compared to wild-type (see MATERIALS AND METHODS). 
technological advances have been recently made in the field of splice-switching antisense-oligonucleotides (ASO), which bind and block cis-acting splicing elements to change splicing and reconstitute the protein levels [49]. Remarkably, among the various splice-switching ASOs that reached clinical trials, the nusinersen ASO to treat spinal muscular atrophy was approved for clinical use by the US Food and Drug Administration in December 2016, strongly demonstrating that ASOs are real therapeutic drugs [50]. ASOs are also being tested for cancer targets such as the apoptotic factor B-cell Lymphoma X [51, 52], pyruvate kinase $M$ [53] and the signal transducer and activator of transcription 3 beta [54].

In this study we aimed to develop a therapeutic agent that could act directly and specifically (in a DNA sequence-specific manner) to correct the splice-switching defect produced by the BIM deletion. The sequencespecificity of therapeutic ASOs may minimize off-target effects, and avoid toxicities associated by other agents reported to overcome $B I M$ deletion-mediated TKI resistance, such as $\mathrm{BH} 3$ mimetics and HDAC inhibitors, but which suffer from clinically significant side-effects [19, 55-58]. Here, our approach was to first identify the cis-acting sequences that regulate BIM splicing within and upstream E3, and guided by this information, to design and test novel splice-switching ASOs to directly correct BIM splicing and restore TKI sensitivity. We found that as many as eight ASOs effectively redirected BIM splicing from E3 to $\mathrm{E} 4$, and reconstitute the TKI-mediated responses in two different CML cell lines. Overall, this work shows that it is possible to manipulate $B I M$ alternative splicing to resensitize cancers to TKIs.

\section{RESULTS}

\section{Identification of cis-acting elements regulating BIM E3 alternative splicing}

We first systematically identified the cis-acting splicing elements in the BIM E3 and upstream intronic region that is common among alleles with or without the 2,903-bp deletion polymorphism. We used the $\Delta 10$ and $\triangle 11 B I M$ minigenes [31], which have E3 and E4 with flanking shortened intronic regions fused to adenoviral $\mathrm{U}$ and $\mathrm{D}$ exonic sequences (Figure 1B). $\Delta 10$ splices like the full-length $B I M$ substrate as it includes the last 322 of the $2,903 \mathrm{bp}$ that are sufficient for the repressive effects of this region, while $\Delta 11$ has this fragment removed to recapitulate the splicing patterns of the 2,903-bp deletion allele. Both $\Delta 10$ and $\Delta 11$ minigenes were used to confirm the effects of deletions and also to identify elements that are specific to the deletion allele, if any. Similar to a previous study [59], in the D ("deletion") series of constructs, we introduced consecutive deletions of 10 nucleotide (nt) from the third nucleotide of E3 (first nucleotide outside the conserved region of the 3 'ss) to the end of this exon. In the SD "staggered deletions" series, the deletions started from the middle of a D deletion to the middle of the next $\mathrm{D}$. The use of $\mathrm{D}$ and SD series reduces the possibility that the changes in E3 splicing conferred by each deletion are due to creation of new junctions rather than to removal of a cis-acting element. We identified several regions with consecutive and/or overlapping deletions which consistently increased or decreased E3/E4 ratio as measured by real-time RT-PCR using junction reverse primers with proven specificity (Supplementary Figure 1A) which also captured the splicing change conferred by the deletion polymorphism (Supplementary Figure 1B). The changes in E3/E4 ratio due to deletions suggest the presence of ESSs or ESEs which covered the vast majority of E3 sequence (Figure 1C, 1D). Encouragingly, the changes in E3/E4 ratios for all deletions in $\Delta 10$ versus $\Delta 11$ were almost perfectly correlated $\left(\mathrm{R}^{2}=0.96\right)$, proving the reproducibility of this assay. All deletions covering the consensus poly(A) signal and flanking sequences decreased E3 splicing, which agrees with the notion that 3 '-end formation and 3 'ss recognition of terminal exons enhance each other [60-62]. We also performed a deletion scan of the Intron 2 region between the 2,903-bp polymorphic fragment and the polypyrimidine tract upstream of E3 (negative deletions, $-\mathrm{D}$ and $-\mathrm{SD}$ ). As expected, deletions of the predicted BPS within -SD1 and-D1 strongly reduced E3/ E4 ratio, yet deletion of upstream sequences had a milder effect, as these segments might contribute to U2 small nuclear ribonucleoprotein (snRNP) binding to the BPS. In summary, here we unveiled many potential enhancers and silencers that regulate E3 inclusion, some strong and some weak (Figure 1D), and with functional implications for TKI responses.

We confirmed the regulatory activity of three identified ESEs, which we termed ESE1, ESE2 and ESE3 as ordered from 5' to 3' of E3 (Figure 1D and Figure 2A). To this end, we introduced point mutations which were not predicted to create any new cis-acting element by using Human Splicing Finder [63]. All these point mutations reduced $B I M$ E3 splicing, mostly recapitulating the effects of the corresponding deletions, and further strengthening the evidence of these sequences as bona-fide ESEs. We next introduced these enhancer sequences in a heterologous exonic context, which is the weak alternative exon within $\mathrm{pSXN}$ minigene whose inclusion relies on an ESE (Figure 2B) [64]. While the control pSXN construct with the original ESE showed complete exon inclusion, removing this ESE only to leave a short linker results in complete skipping of this exon, as visualized by radioactive RT-PCR followed by PAGE (Figure 2B, lanes 1-2). Introduction of ESE1, ESE2 or ESE3 increased the inclusion of the $\mathrm{pSXN}$ exon compared to linker control, with ESE2 acting as the strongest enhancer (Figure 2B, lanes 3, 7 and 9). The constructs with the ESEs containing one of the point mutations tested above 
A

ESE1 (Enhancer 1)

D1+SD1 regions, E3 nt 03-17

Wt: GUCAUCCUAGAGGAU

Mt1: GUAAUCAUAGCGGAU

Mt2: GUCAGCAUAGCGGAU

Mt3: GUCAUAAUAGCGGAU

\section{ESE2 (Enhancer 2)}

SD9+SD10 regions, E3 nt 88-107

Wt: AAGAUACAGAACAACUCAAC

Mt1: AACAUAAUUAACCAUUCAAC

Mt2: AAGAUAAUUAAUCAUUCAAC

Mt3: AAGAUAUCUAAUAACUCCAC

Mt4: CAUACUCAUAAUAACUCCAC

ESE3 (Enhancer 3)

SD11+D12 regions, E3 nt 108-122

Wt: CACAAGGAUUUCUCA

Mt1: CAUAAGCAUUUCCCA

Mt2: CAUAACCAUUUCUCA

Mt3: CACUAGCAUUUUCUCA

Mt4: CACUAUCAUUUCUCA
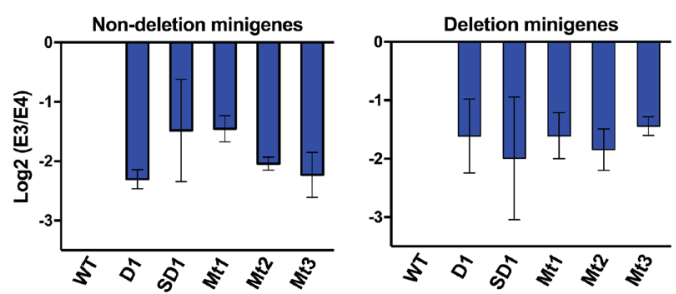

B
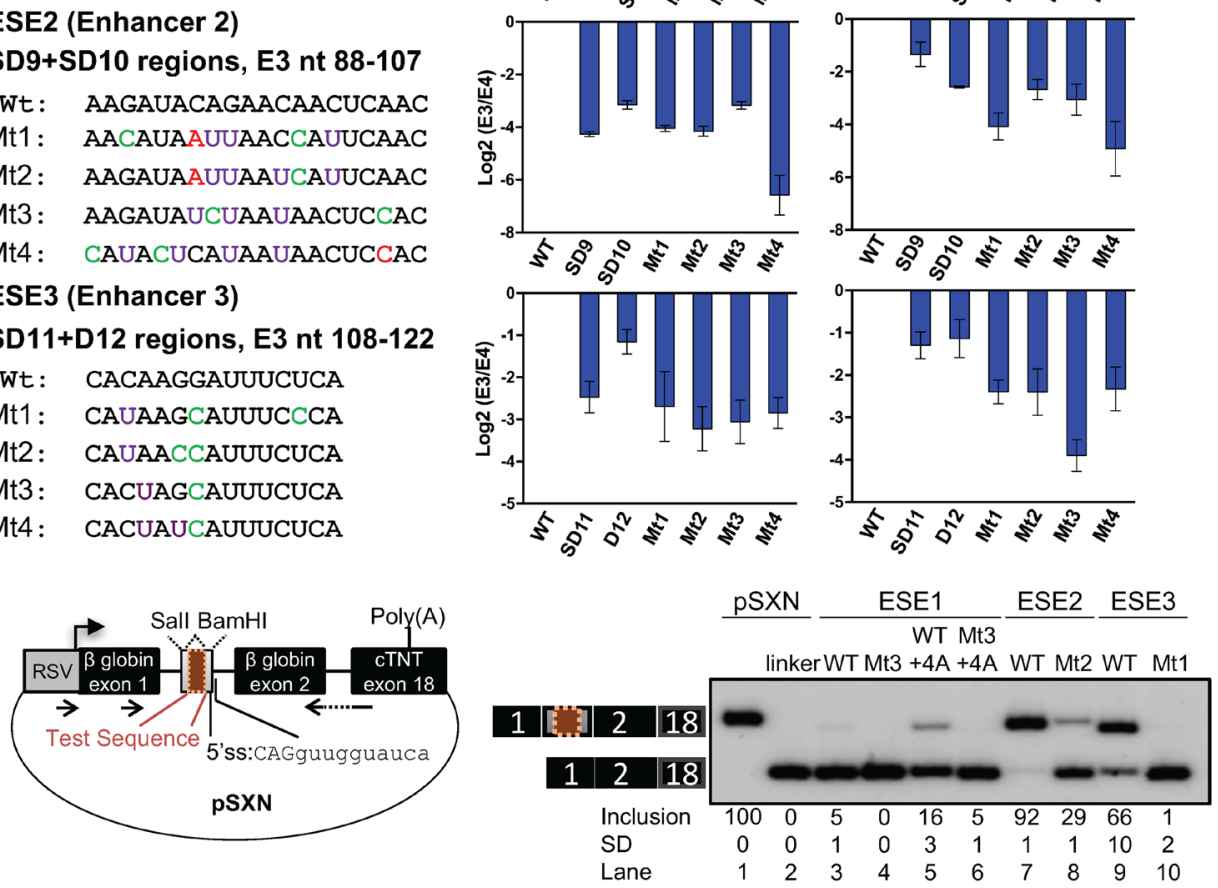

C
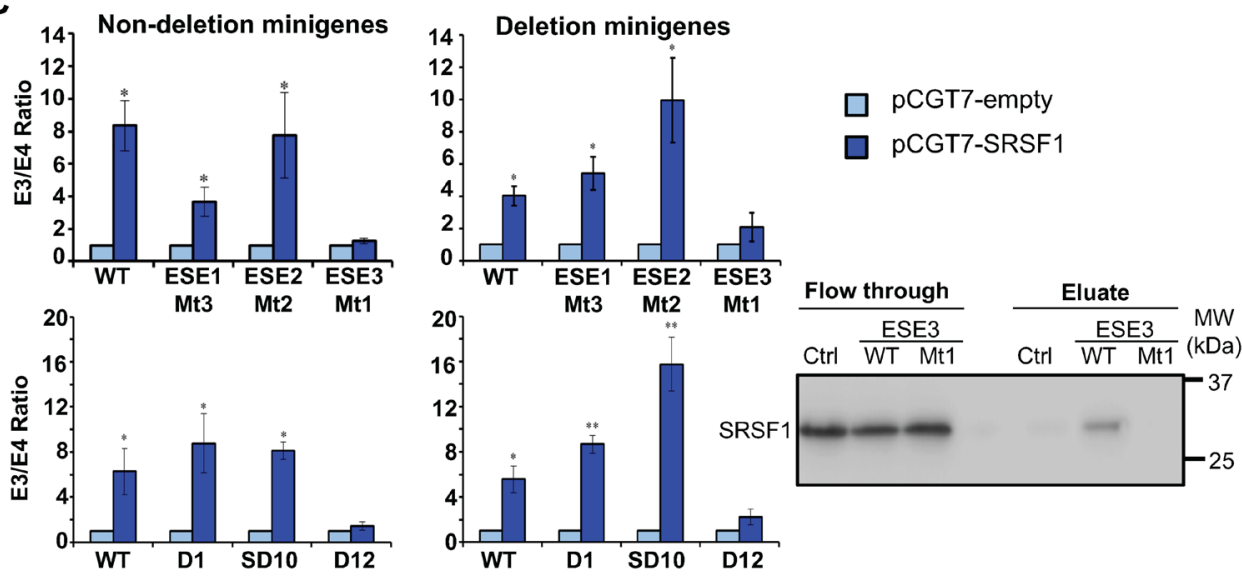

Figure 2: Confirmation of ESE1-3 as bona fide BIM E3 enhancers, and SRSF1 induction of E3 inclusion via ESE3. (A) Left, list of wild-type ESEs and the corresponding mutant sequences with their position relative to the first nucleotide of E3. Point mutations are highlighted in different colors. Right, real-time RT-PCR data for $\log 2$ E3/E4 ratios for each construct, indicating that the mutations reduced the ratios to similar extend as the overlapping deletions. All deletions or point mutations are significant with $\mathrm{P}<0.05$ compared to WT minigene using Student's t-test. (B) Left, diagram of the pSXN plasmid, in which test sequences (maroon box) were cloned into the indicated restriction sites in the gray exon. Arrows depict RT-PCR primers for detecting minigene transcripts. Right, RT-PCR data of K562 cells transfected with the indicated pSXN constructs. pSXN-13 with ESE (lane 1) and the pSXN-linker (lane 2) were respectively used as positive and negative controls. Exon inclusion reflects the enhancing effect of the inserted sequences (lanes 1, 3, 5, 7, 9), while absence or reduction of exon inclusion implies the disruption of the enhancer activity (lanes 2, 4, 6, 8, 10). Inclusion averages and Standard Deviations at the bottom were derived from at least three independent replicates (samples from different transfections). (C) Left, real-time RT-PCR data for E3/E4 ratios for ESE deletion and point mutant constructs co-transfected with pCGT7-empty or pCGT7-SRSF1 plasmids. All constructs except ESE3 D12 deletion and Mt1 point mutation show significant increase in E3/E4 ratio with SRSF1 overexpression (P $<0.05$ using Student's t-test). Note that the Y axis in this panel is not on Log 2 scale. Right, RNA pulldown and western blot shows binding of SRSF1 to ESE3 WT which is disrupted in Mt1. This is a representative western blot of three independent pulldowns. 
reduced the inclusion of this exon, consistent with these mutations disrupting the enhancers (Figure 2B, lanes 7-10). ESE1 was very weak in this context, which could be compensated by a point mutation adding another consensus nucleotide to the 5'ss ( $\mathrm{Wt}+4 \mathrm{~A})$, and then further disrupted by $\mathrm{mt} 3$ (Figure 2, lanes 3-6). All in all, these point-mutation and heterologous context experiments strongly supported the three ESEs within BIM E3, with ESE2 as the strongest and ESE1 as weakest, and set the stage for testing of therapeutic ASOs to overcome BIM deletion resistance.

By co-transfecting an SRSF1-expression plasmid [65] together with the BIM $\Delta 10$ and $\Delta 11$ minigenes, we found that overexpression of this splicing factor largely increased E3 splicing (Figure 2C, Supplementary Figure $1 \mathrm{C})$, indicating that these minigenes contain the SRSF1 responsive element. Indeed, while the minigenes with ESE1-2 deletions and point mutations responded to SRSF1 levels to a similar degree as wild-type minigenes, the deletion or mutation of ESE3 abolished the SRSF1 effects, indicating that ESE3 contains the SRSF1 responsive element. The in silico tool Human Splicing Finder [63] predicted the binding of SRSF1 to ESE3 (motif: CACAAGG) but not to mut 1 ESE3. Consistently, RNA pulldown showed SRSF1 binding to wild-type but not mut 1 ESE3, arguing that the SRSF1 promotion of E3 inclusion might be via direct binding to ESE3. Thus, our study also identified one trans-acting factor, which happens to be a proto-oncogene $[32,44]$, that regulates one of the three confirmed ESEs.

\section{Many splice-switching ASOs identified by coarse walk around $B I M \mathrm{E3}$ in $\mathrm{K562}$}

Next we performed a coarse ASO walk covering BIM E3 and flanking intronic regions (Figure 3A). We designed a total of 67 ASOs 18-nt long uniformly modified with 2'-O-methoxyethyl (MOE) nucleotides and a phosphorothioate backbone, and spaced by $5 \mathrm{nt}$ from one another (5-nt walks, Supplementary Table 1). ASOs 1-14 covered the end of Intron 2, ASOs 15-60 covered E3 and ASOs 61-67 the region after E3. ASOs targeting the center of the polyU tract (with 17-21 Us) at the E3 3'ss were not synthesized because of the low specificity of this sequence.

We first tested all 67 ASOs in the K562 CML cell line, which lacks the BIM deletion allele and is thus sensitive to imatinib. Consistent with this notion, endogenous BIM transcripts show high E4 and lower E3/ E4 ratios compared to the imatinib resistant cells, and E4 transcripts increase upon imatinib (Supplementary Figure 2A). Western blotting showed differences in BIMEL levels which correlated with imatinib reponses (Supplementary Figure 2B). Inclusion of E3, E4 and exon 2A (E2A) was measured by real-time RT-PCR upon ASO nucleofection. Most ASOs did not consistently alter the total levels of BIM mRNA as measured by E2A-containing transcripts (Figure 3B, bottom graph). As many as 20 ASOs significantly decreased E3 inclusion (Figure 3B, top graph, blue ASOs), and 34 ASOs also decreased the E3/E4 ratio (Figure 3B, third graph), which mapped to the end of Intron 2 (ASO 11-14), from the intron-exon junction to the middle of E3 (ASO 15-29, 31-39), and to the end of E3 including the poly(A) signal (ASO 44$45,52-55)$. Even though these 34 ASOs decreased the E3/E4 ratio, none significantly increased E4 splicing (Figure 3B second graph), likely because E4 inclusion is already high in K562 (Supplementary Figure 2A). Finally, five ASOs significantly increased the E3/E4 ratio by targeting different regions of the transcript as shown in red (Figure 3B third graph, ASO 3, 42, 64, 65 and 67). These E3-activating ASOs likely target ISSs or ESSs, and have potential therapeutic applications for diseases with excessive BIM-dependent apoptosis. Nevertheless, this initial ASO walk identified numerous ASOs that reduce the E3/E4 ratio, with potential to resensitize resistant cells to TKIs.

\section{Imatinib and ASO treatment in KCL22 identifies the eight best ASOs that switch BIM splicing}

The 39 ASOs that change BIM splicing (Supplementary Figure 3A) were next tested in the imatinib-resistant CML cell line KCL22, which is heterozygous for the 2,903-bp deletion allele, and expresses $B I M$ transcripts with a higher E3/E4 ratio compared to K562 (Supplementary Figure 2A). From the 34 ASOs that decreased E3/E4 ratio in K562, only 2 did not do so in KCL22 cells (Supplementary Figure 3B, ASOs 11 and 12). Nevertheless, we did not detect a net increase in E4 levels by any of the 32 effective spliceswitching ASOs. In addition, from the 5 ASOs that increased $\mathrm{E} 3 / \mathrm{E} 4$ ratio in $\mathrm{K} 562$, only one did fail to do so in KCL22 (Supplementary Figure 3B, ASO 3). The splicing ratios upon ASO nucleofection in KCL22 were largely consistent with those in K562.

We next tested the 32 ASOs that decrease E3/E4 ratio (Figure 4A) in KCL22 cells treated with imatinib. This TKI directly inhibits the $B C R-A B L 1$ fusion oncogene by blocking its ATP-binding pocket and repressing its signaling $[66,67]$, thereby upregulating BIM at transcriptional and posttranslational levels to induce CML cell death $[8,12$, 68]. However, in KCL22 cells, the imatinib-induced BIM upregulation is much smaller because of the deletion allele (Supplementary Figure 2), thus not enough to trigger apoptosis. Upon nucleofection of KCL22 cells, and in the presence of imatinib, all 32 ASOs strongly decreased BIM E3 and the E3/E4 ratio (Figure 4B and Supplementary Figure 4B). Remarkably, eight ASOs significantly increased total E4 levels which is necessary for these ASOs to restore functional BIM levels (as E4 encodes the pro-apoptotic $\mathrm{BH} 3$ domain). These ASOs mapped to the predicted BPS 
A

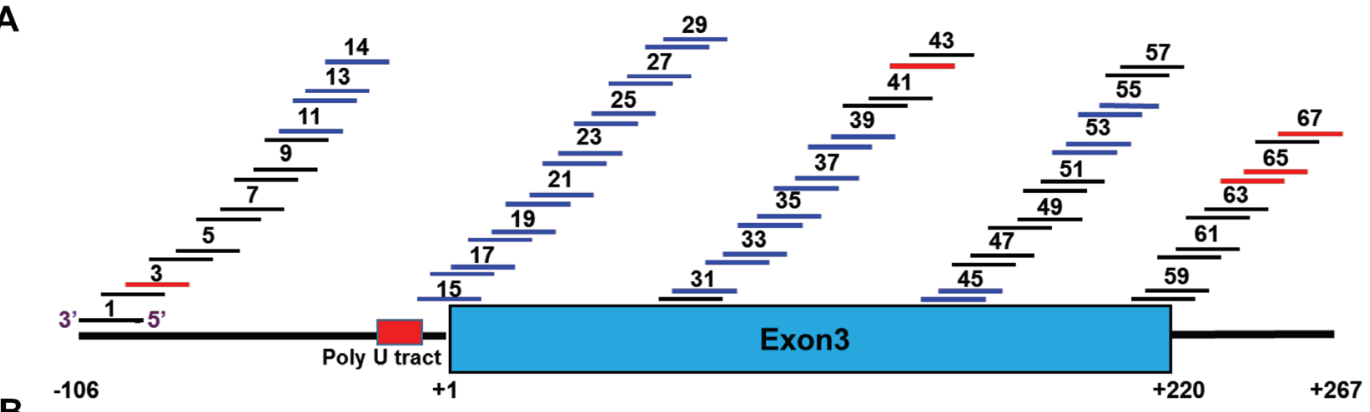

B
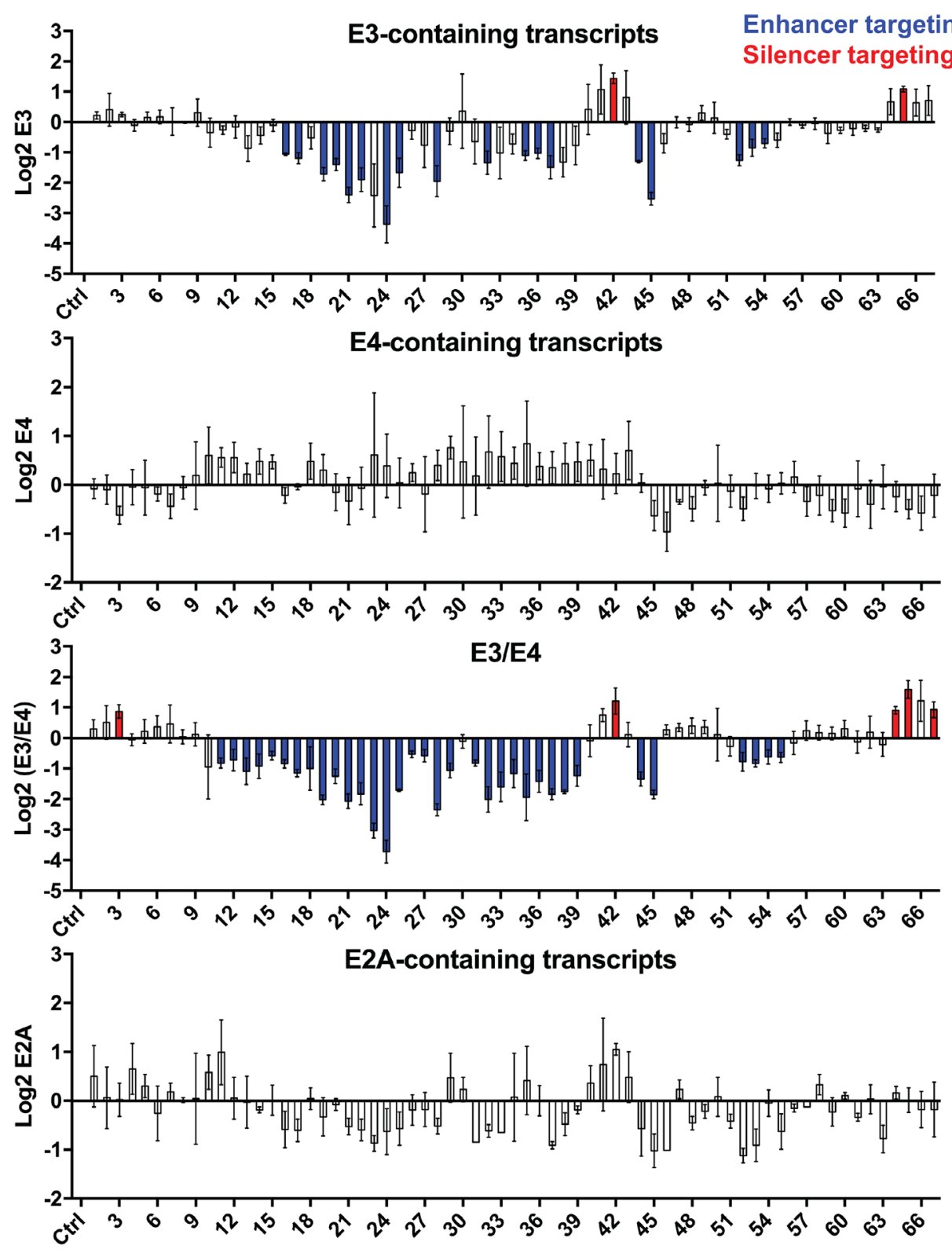

Figure 3: Coarse ASO walk to switch BIM splicing in K562 cells. (A) Design of the 67 ASOs covering Intron 2 (left bold line), E3 (blue box) and intronic region downstream of E3 (right bold line). ASOs are shown as numbered short lines, in which the color depicts effects on BIM splicing: black denotes neutral ASOs which do not change splicing, blue indicates ASOs that increase E3/E4 ratio by likely targeting a splicing enhancer, and red indicates ASOs that decrease this ratio, likely blocking a silencer. The nucleotide coordinates relative to the 5' end of E3 are indicated at the bottom. (B) Log 2 real-time RT-PCR data for transcripts containing E3, E4, and E2A, as well as the E3/E4 ratios. The ASOs 1-67 are ordered from left to right. Ctrl, control ASO with no target in human cells. ASOs that significantly alter the exon amounts relative to control are colored in blue or red as in panel A. All values derived from three independent transfection samples. 
in Intron 2 for ASO 13, the Intron 2-E3 junction for ASO 15 , the beginning of E3 for ASO 18, and two internal E3 regions for ASOs 28-29,33 and ASOs 52-53. These eight shortlisted ASOs were subsequently tested for BIM isoform profiling and effects on apoptosis.

\section{The eight shortlisted BIM ASOs enhance imatinib-mediated killing of KCL22 cells}

Detailed tests of the eight shortlisted ASOs in imatinib-treated KCL22 cells by radioactive PCR [32] showed consistent results with the real time PCR (Figure 5A). The BIM E3-containing isoforms are divided into the predominant $\gamma 2$ and the faint $\gamma 1$, and both are downregulated upon imatinib treatment. All eight ASOs virtually abolished expression of $\gamma 1$, and further reduced $\gamma 2$, with ASOs 28, 29, 33 and 53 showing the strongest repression. In turn, all eight ASOs increased mRNA for BIML, and 15, 18, 28 and 53 also upregulated BIMEL and BIMS. By comparing the two merged E3containing isoforms (BIM $\gamma$ isoforms, with $\gamma 1$ and $\gamma 2)$ and the three E4-containing isoforms (BIMEL, BIML and BIMS), we detected a clear and specific ASO-mediated downregulation of $B I M \gamma$ and upregulation of $\mathrm{BH} 3-$ containing BIM isoforms.

Next we assessed the effects of the eight shortlisted ASOs in cell viability, by measuring the percentage of dead cells by trypan blue (Figure 5B). Once again, real-time RTPCR confirmed upregulation of E4-containing transcripts upon ASO treatment (Supplementary Figure 5A). Trypan blue exclusion revealed that imatinib decreased the number of live KCL22 cells very slightly, and control ASO further reduced it, suggesting unspecific yet mild toxic effects of the ASO nucleofection. Encouragingly, imatinib-treated

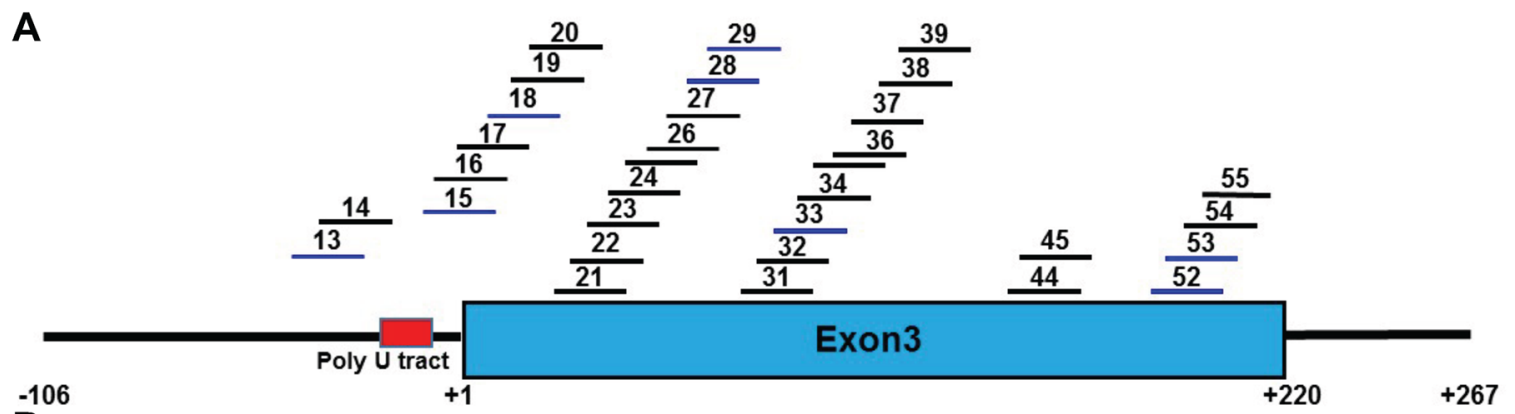

B

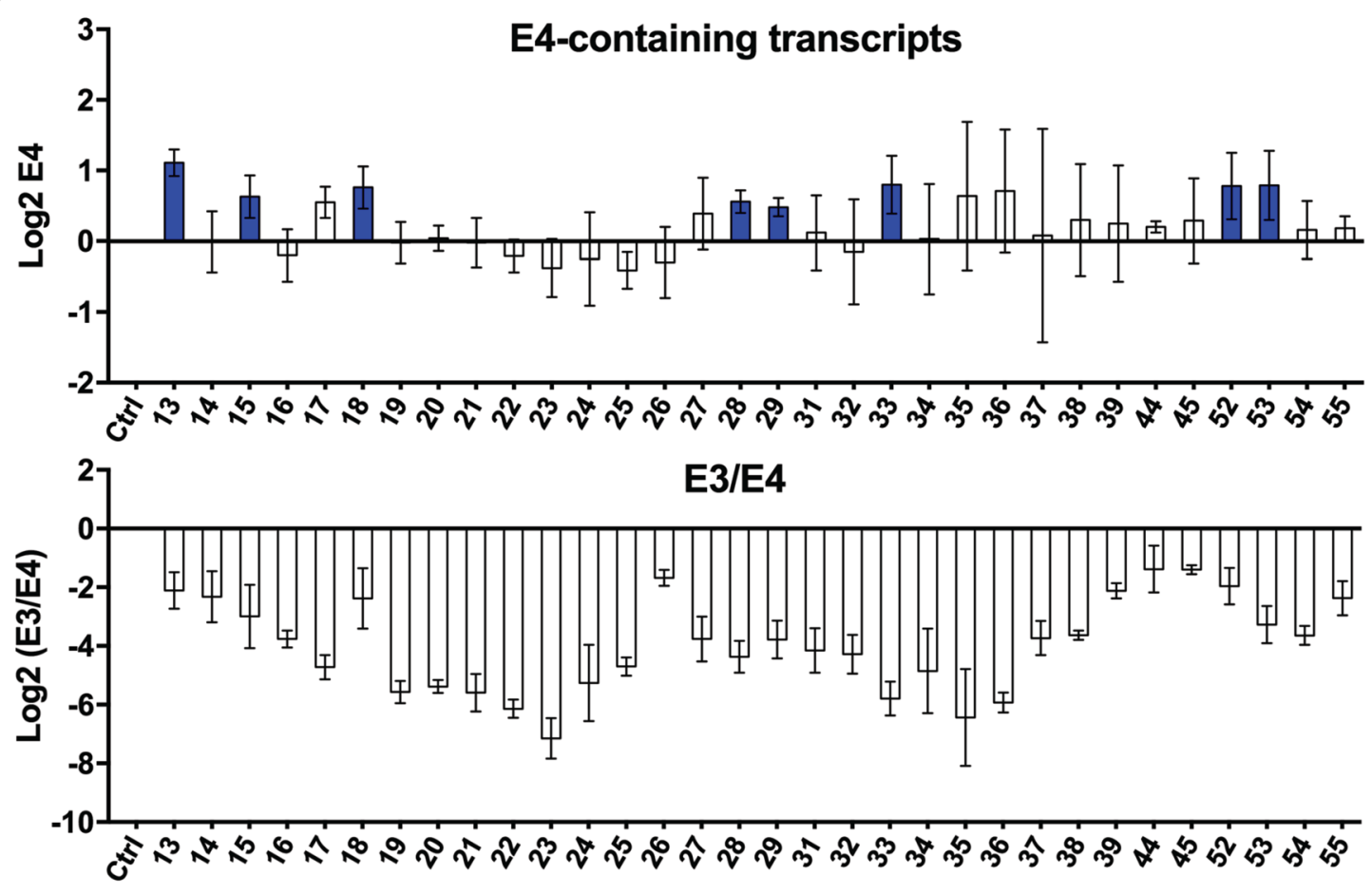

Figure 4: ASOs in KCL22 CML cell line after administration of imatinib. (A) Summary of 32 shortlisted ASOs that decrease E3/E4 ratio (blue) in both K562 and KCL22. Format as in Figure 3A. (B) Log 2 real-time RT-PCR measurements of transcripts containing $\mathrm{E} 4$ as well as the E3/E4 ratios. Ctrl, control ASO. All tested ASOs reduce the E3/E4 ratio to different extents. ASOs that significantly increase the levels of E4 relative to control are colored in blue. All values derived from three independent transfection samples. 
KCL22 cells transfected with the eight ASOs showed higher levels of cell mortality, suggesting ASO-specific cell killing associated to BIM splicing switch. The ASOs enhanced imatinib-mediated cell killing by $9-16 \%$, which is small but statistically significant. Bromodeoxyuridine pulse labeling experiments ruled out that imatinib and ASO-treated cells were arrested in any stage of the cell cycle (Supplementary Figure 6 and Supplementary Table 2). Furthermore, Western Blotting also confirmed the enhanced cell death triggered by the eight ASOs (Figure 5C). As expected, BCR-ABL1 signaling was effectively inhibited by imatinib treatment [69-72], as evidenced by decreased STAT5 phosphorylation. Nevertheless, the low levels of proapoptotic BIM associated to the deletion polymorphism render these cells largely resistant to cell death [19], and here we show that this resistance is reversed by the eight ASOs. We also detected higher cleaved caspase 3 and Poly (ADP-ribose) polymerase $(P A R P)$ as well as higher BIMEL and BIML isoforms associated with nucleofection of the shortlisted ASOs, consistent with enhanced apoptosis. As expected, imatinibdriven apoptosis in CML cells is induced by increased cleaved caspase 3 without a major change in total caspase 3 [73]. Furthermore, DNA fragmentation increased by three selected ASOs which were 13, 15 and 18 (Figure 5D). Altogether, these results show that the changes in $B I M$ splicing by the eight effective ASOs also specifically induce imatinib-driven cell death in resistant CML cells.

\section{The eight shortlisted BIM ASOs enhance imatinib-mediated killing in $B I M$ deletion- polymorphism containing K562 cells}

To validate our findings in KCL22 cells, we next tested the select ASOs in K562 clones which were rendered TKI-resistant by the presence of the BIM deletion polymorphism in either one (K562-BIM $\left.{ }^{12+/}\right)$ or two alleles $\left(\mathrm{K} 562-\mathrm{BIM}^{\mathrm{I2-}-\mathrm{s}}\right.$ ) [19] (Figure 6). The number of deletion alleles corresponded with higher E3/E4 ratio compared to parental K562-BIM ${ }^{\mathrm{I2+/+}}$ cells (Supplementary Figure 2). Compared to control ASO, the eight ASOs resensitized both K562-BIM ${ }^{12+/-}$ and K562-BIM ${ }^{12-/-}$ cells to imatinib-induced cell death (Figure 6A). Importantly, the cell death counts for these samples almost reached the values of imatinibsensitive K562-BIM ${ }^{12+/+}$ cells without the BIM deletion (compare gray bar in 'Cell only' or ASO-Ctrl to orange or blue bars for ASO-13-53). Thus, the imatinib-driven and ASO-enhanced cell mortality in resistant cells is not large but mimics what is seen in sensitive cells with imatinib alone, arguing for the biological effect of these ASOs. Some of these ASOs upregulated BIM E4-containing transcripts, except ASO-33 and perhaps others in K562$B I M^{12+/-}$ (Supplementary Figure 5B). In addition, Western blotting of K562-BIM ${ }^{\mathrm{I2}-\mathrm{I}_{-}}$cells showed very clear increases in BIMEL (which contain the $\mathrm{BH} 3$ domain), as well as cleaved caspase 3 and cleaved PARP upon combined imatinib and BIM ASO treatment (Figure 6B). Overall, the results in the artificially induced imatinib-resistant K562$B I M^{\mathrm{I} 2+/-}$ and $\mathrm{K} 562-B I M^{\mathrm{T} 2-/-}$ cells are consistent with the intrinsically-resistant KCL22 cell line. In conclusion, our data in K562 and KCL22 cells show that the eight ASOs switch BIM splicing, increase total levels of E4-containing isoforms, and also resensitize BIM deletion-containing CML cells to imatinib-induced apoptotic cell death.

\section{DISCUSSION}

This study shows that it is feasible to switch BIM splicing so as to enhance production of proapoptotic BIM isoforms, and thereby resensitize resistant BIM deletion-containing CML cell lines to imatinib. The eight most efficient splice-switching ASOs (Figure 7A) had similar effects in up to four different cell lines, including the naturally occuring imatinib-sensitive K562 (K562$B I M^{\mathrm{I2+/+}}$ ) and the imatinib-resistant KCL22 cells, as well as two artificially-created K562 cell lines with the 2,903bp deletion polymorphism [19]. The increase in E4containing transcripts was accompanied with enhanced cell mortality and in apoptotic cell markers. We cannot exclude the possibility that the ASO-mediated cell mortality was diluted by efficient cell death which eliminated cells early on, but we did rule out a cell cycle arrest by BIM ASOs. Despite that some of the effects being small, the direct comparison of the imatinib plus ASO treatment between sensitive K562-BIM ${ }^{12+/+}$ and either K562$B I M^{12+/-}$ or K562-BIM ${ }^{\mathrm{T2-/}-}$ cells suggests that these ASOs can reverse almost all resistance conferred by the Intron 2 deletion polymorphism. Nevertheless, we predict that further optimizations of ASO efficiency can be achieved by 'microwalks', which encompass small ASO sequence variations (produced by sliding the targeted sequences by one or few nucleotides) or slight changes in their length [74]. Perhaps ASO chemistries other than the 2'MOE or combinations of ASOs could also help enhance the ASO effects on apoptosis. In any case, these ASOs would only be used in the clinic in combination with imatinib or other TKIs, and perhaps with other emerging drugs such as BH3 mimetics or histone deacetylase inhibitors [75-77].

These eight ASOs should be further tested in primary tumors and especially in mouse models with BCRABL1 driven cancers [78]. The MOE-phosphorothioate chemistry confers ideal properties such as high specificity, molecular potency and resistance to degradation, while maintaining tolerability. Importantly, these ASOs are taken up by animal cells in the absence of a specific delivery agent by an as yet uncharacterized receptor-mediated endocytosis. In fact, ASOs can be systemically delivered in mice via either subcutaneous or intravenous injections, or via intrathecal injections for delivery into central nervous system, efficiently switching splicing in difficult cells like neurons [74, 79, 80]. Remarkably, ASOs were recently microinjected in utero for fetal delivery to mouse 
A

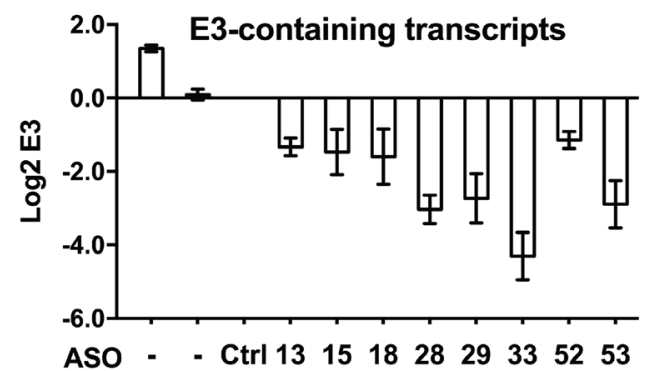

${ }^{2.0}$ E4-containing transcripts

Imatinib - + + + + + + + +

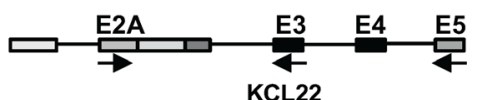

B

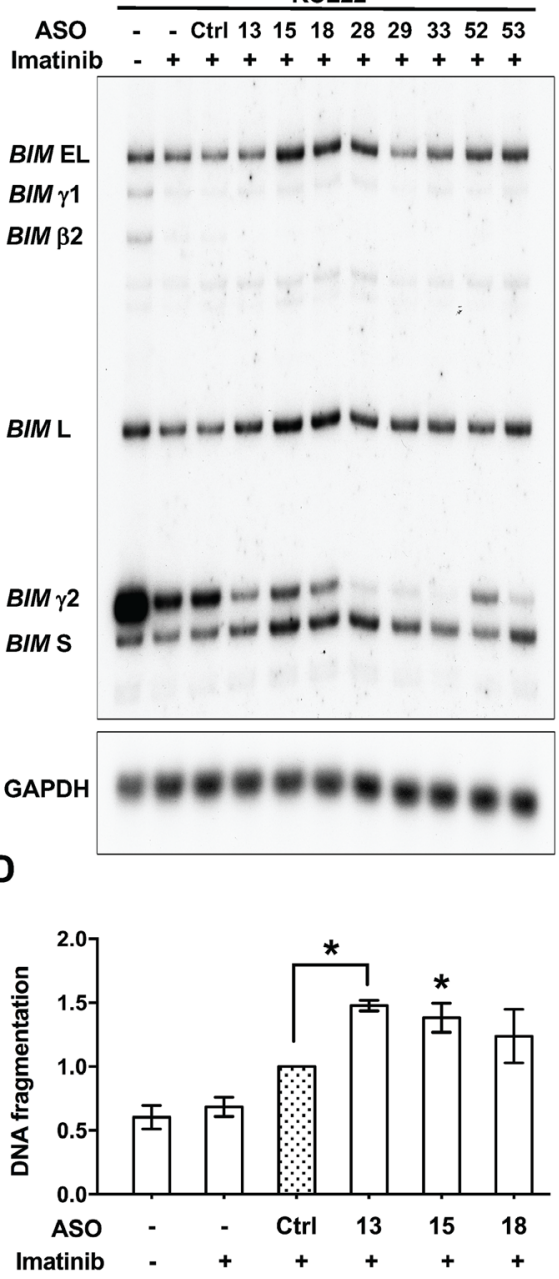

C

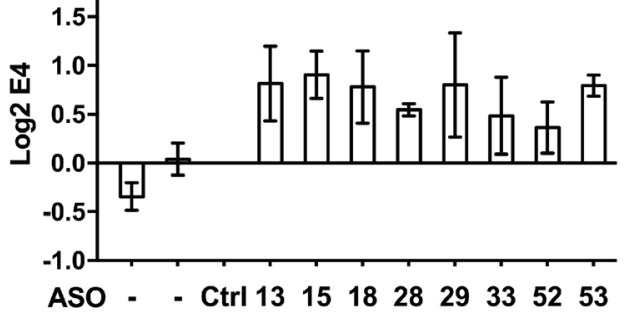

Imatinib - + + + + + + + +
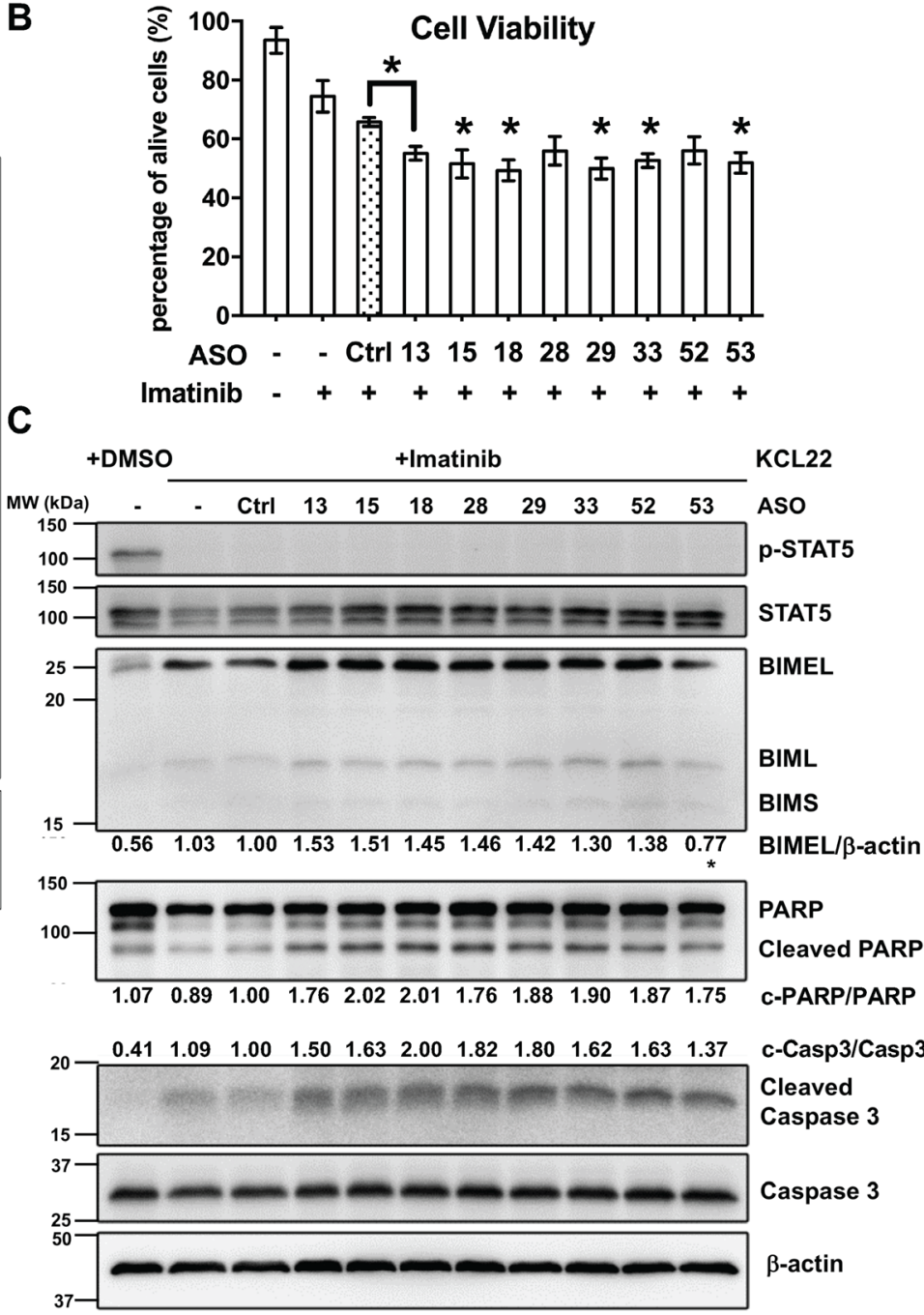

Figure 5: Detailed characterization of the effects of eight shortlisted ASOs in KCL22 cells treated with imatinib. (A) Radioactive RT-PCR for BIM isoforms upon ASO nucleofection. As in the schematic, BIM RNA isoforms were amplified with a common forward primer in E2A and two reverse primers, one in exon 5 for E4-containing isoforms (EL, L and S) plus an isoform without E4 ( $\beta$ ), and one in $\mathrm{E} 3$ for $\operatorname{BIM} \gamma(\gamma 1$ and $\gamma 2$ ). Top graphs show Log 2 aggregate quantification of the bands for E3- and E4-containing isoforms. GAPDH RT-PCR was used as control for equal loading. (B) Cell viability assay by trypan blue in KCL22 cells treated with imatinib and ASOs. Graph shows the percentage of viable cells for each condition. Asterisks indicate significant difference between Ctrl and specific ASO treatments ( $\mathrm{P}<0.05$, Student's T Test). (C) Western blotting of imatinib- and ASO-treated KCL22 cells for markers of BCR-ABL1 signaling like phosphorylated (p-) STAT5 and total STAT5, as well as apoptotic markers like BH3-containing BIM isoforms, full-length and cleaved PARP and caspase 3. $\beta$-actin was used as loading control. This blot is representative of two experiments. Mean percentages indicate BIMEL levels normalized to $\beta$-actin, cleaved caspase 3 normalized to total caspase 3 , and cleaved PARP normalized to total PARP. We did not see upregulation of BIMEL with ASO-53, but upregulation of cleaved caspase 3 and PARP were clear. (D) DNA fragmentation assay in KCL22 cells treated with $0.6 \mu \mathrm{M}$ imatinib shows enhanced DNA fragmentation by ASO 13, 15 and 18. 
A
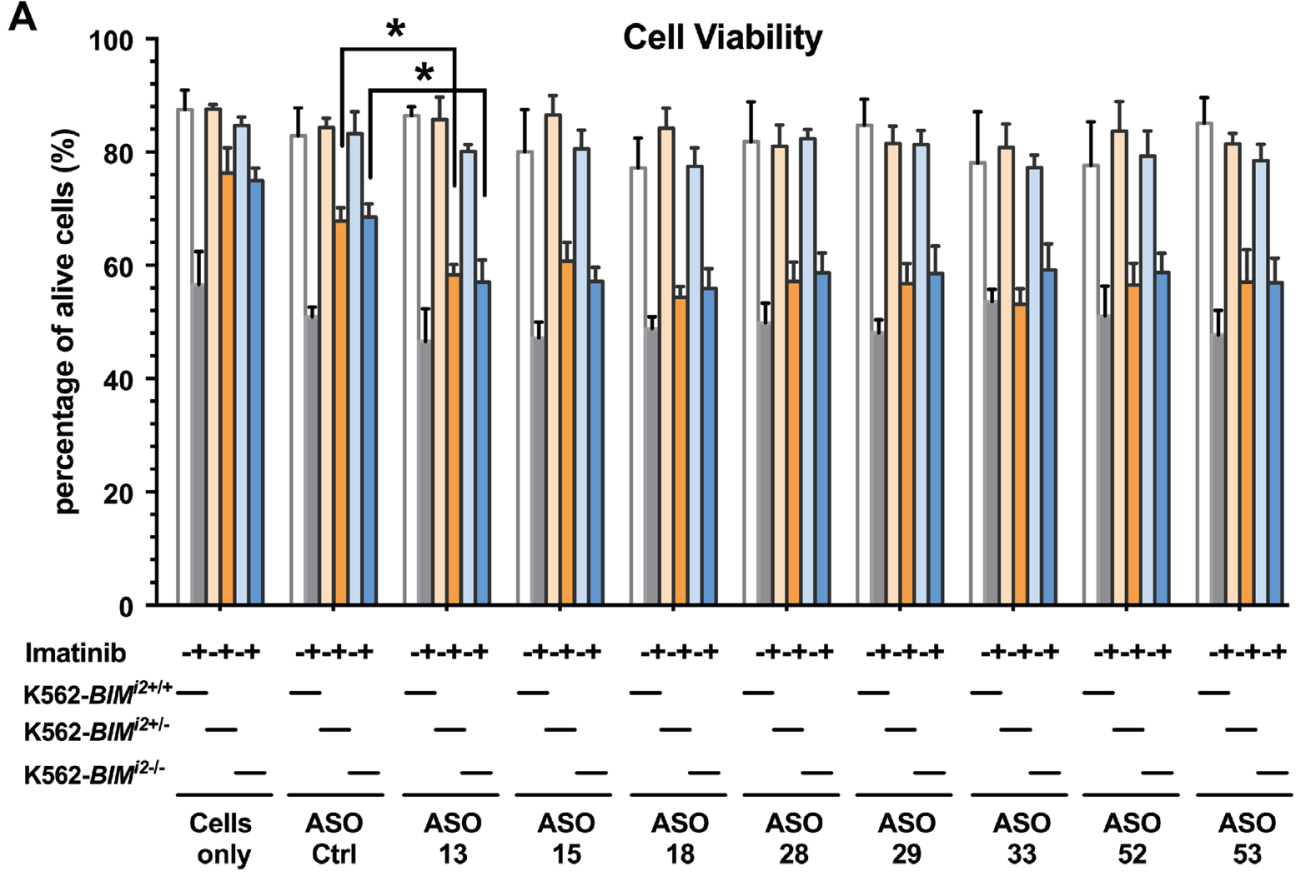

B
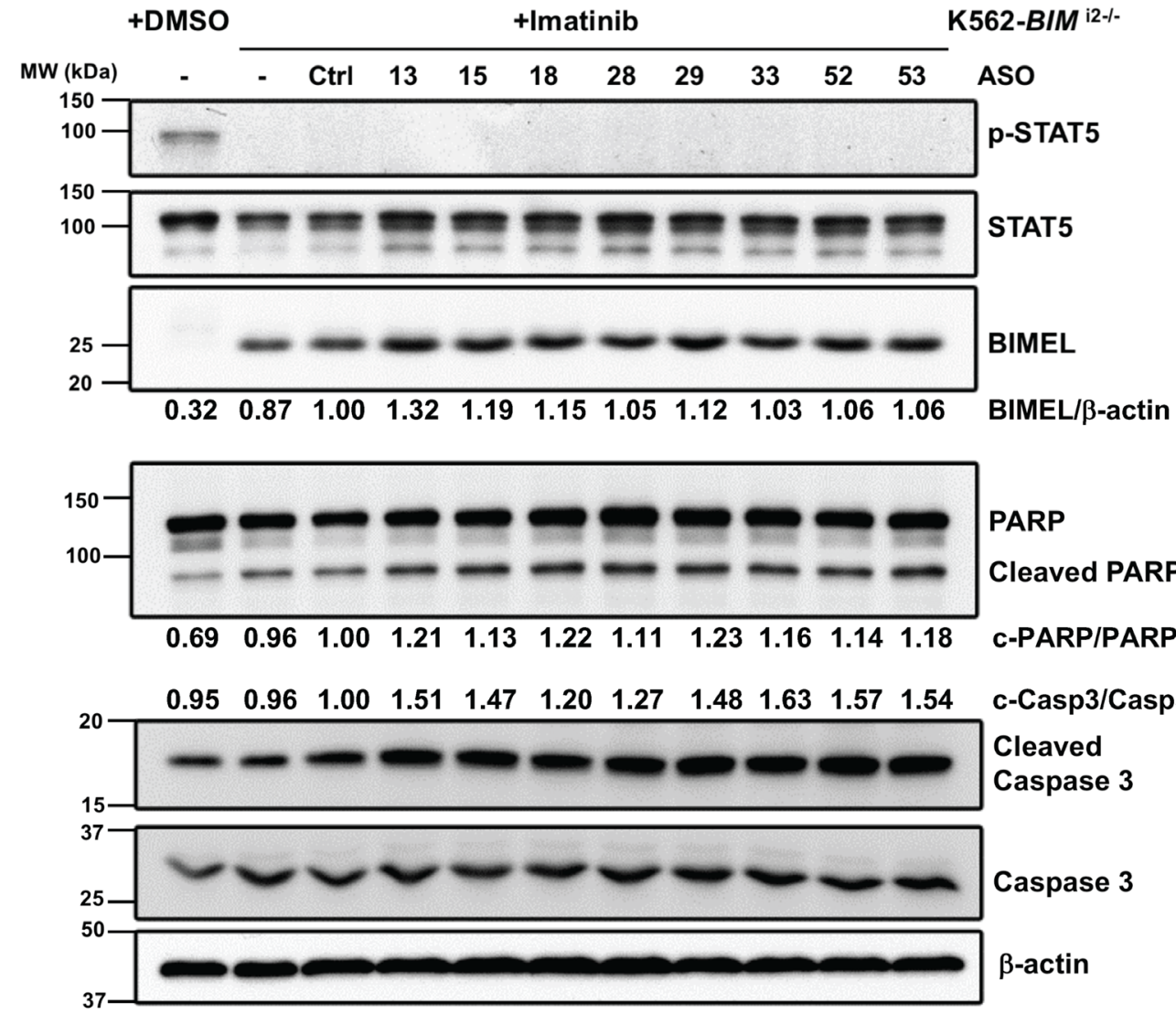

c-Casp3/Casp3

Cleaved

Caspase 3

Caspase 3

Figure 6: Analysis of shortlisted ASOs in edited K562 cells bearing the BIM deletion alleles and hence resistant to imatinib. (A) Cell viability results for wild-type K562 (K562-BIM $\left.{ }^{12+/}\right), \mathrm{K} 562-B I M^{12+/-}$ and $\mathrm{K} 562-B I M^{12-/-}$ cells treated with combinations of imatinib and ASOs. ASOs resensitize deletion bearing K562 cells to imatinib up to levels that are close to those for sensitive wild-type K562 cells. Asterisks indicate significant difference between Ctrl and specific ASO treatments ( $\mathrm{P}<0.05$, Student's T Test). (B) Western blotting for BCR-ABL1 signaling and apoptotic markers for K562-BIM ${ }^{12-1}$ cells plus imatinib and ASOs. This blot is representative of two experiments. We also indicated mean percentages of BIMEL and cleaved caspase 3 and PARP. 
amniotic cavity, showing effects in the newborns even weeks after birth [81]. These recent developments in ASO delivery routes suggest that this technology might extend to cancer cells as well.

In the context of human cancers where the BIM deletion allele predicts poorer therapeutic responses and clinical outcomes, such as in CML or EGFR-NSCLC, the splice-switching ASOs we have identified may be used in combination with appropriate TKIs to overcome the negative effects of the BIM deletion. In addition, and in contrast to somatically acquired mechanisms of resistance which arise during the course of therapy, the germline nature of the BIM deletion would allow patients who harbor the deletion to be identified and treated when they first present. Furthermore, in the case of EGFR-NSCLC where tumor tissue may be hard to obtain, genotyping for the $B I M$ deletion may be performed on normal tissue, e.g from peripheral blood mononuclear cells or even a buccal swab. Because other drugs have also been described to overcome the effects of the BIM deletion, including so-called BH3 mimetic drugs and histone deacetylase inhibitors, it may also be possible to combine spliceswitching ASOs with either of these agents to further enhance their effects, although this might be at the risk of increased toxicity $[19,55-58]$.

In addition to providing proof-of-concept for spliceswitching ASOs, this study also presents new mechanistic insights into the alternative splicing regulation of an important proapoptotic factor. Our deletion scan in the BIM minigenes revealed a number of regulatory E3 cis-acting splicing elements. Notably, some of the effective ASOs that reduced the E3/E4 ratio indeed map to ESEs and other intronic or exonic elements important for E3 inclusion, such as the predicted BPS and the Intron 2-E3 junction as

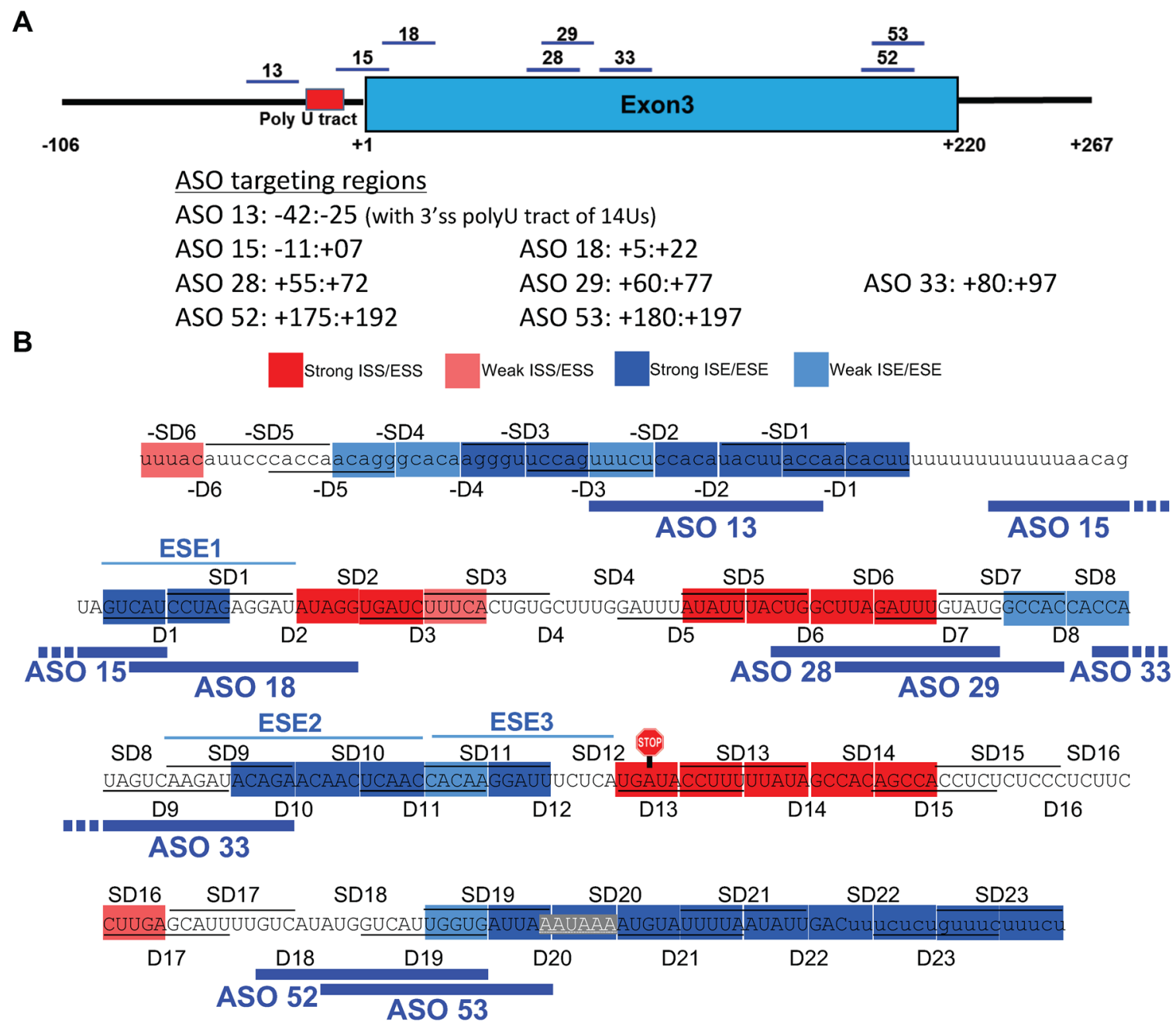

Figure 7: Summary of the map of cis-acting elements and effective splice-switching ASOs for BIM E3 splicing. (A) Schematic mapping of the shortlisted ASOs which upregulate E4-containing transcripts and increase the imatinib-driven CML cell apoptosis. Their coordinates relative to the first nucleotide of E3 $(+1)$ are also indicated. (B) Overlay of the map of splicing enhancers and silencers by deletion scan with the eight shortlisted ASOs, which mostly target 'blue' enhancers or other sequences with similar activity, such as BPS, 3'ss and polyadenylation signal. 
part of the 3'ss (Figure 7B). The BPS and 3'ss targeting ASO-13 and ASO-15 very likely abolish recognition by the canonical splicing factors such as U2 snRNP and $\mathrm{U} 2$-auxiliary factor (U2AF) heterodimer, respectively. Furthermore, the disruptive effects of deletions at the polyadenylation signal and neighboring sequences on E3 inclusion reflect the synergistic stimulation between 3 '-end formation and splicing [60-62]. The canonical AAUAAA polyadenylation signal was only very recently proven to be bound by the Cleavage and Polyadenylation Specificity Factor (CPSF) subunits CPSF30 and Wdr33, instead of CPSF160 [82]. Mutations in the polyadenylation signal repress in vitro splicing of the last intron [62]. The synergistic stimulation of splicing and 3'-end formation could be attributed to the interactions between U2 snRNP and CPSF [60], or between U2AF65 and Cleavage Factor Im 59KDa [61]. Last, splicing and 3'-end formation are cotranscriptionally coupled as also characterized in cell-free extracts $[83,84]$. The ASOs targeting the polyadenylation signal and downstream sequences did not efficiently switch BIM splicing, probably because of the AU richness of these target sequences may lead to inefficient recognition, or to diversion of ASO binding to other AU-rich sequences. Notwithstanding this, ASO-52 and ASO-53, targeting more GC-rich sequences upstream of the AAUAAA in E3, switched splicing and increased imatinib-driven apoptosis, likely by interfering with CPSF binding.

ESE1-3 were further supported by point mutations also reducing the E3/E4 ratio, and by their splicing enhancer activity recapitulated in the heterologous pSXN context [64]. Direct comparison of these three ESEs in pSXN revealed their intrinsic strengths, showing that ESE2 is the strongest while ESE1 is very weak in this context, despite that ESE1-targeting ASO-18 showed optimal effects in splicing and imatinib-induced cell death. The apparent weakness of ESE1 in pSXN could be due to its context dependency, as its very close proximity to the 3'ss may facilitate efficient enhancement of BIM E3 inclusion. Alternatively, insertion of ESE1 into the pSXN internal exon may have created a new junction with silencing activity, or its proximity to the 5'ss of this small exon sterically reduced $\mathrm{U} 1$ binding, as $\mathrm{U} 1$ snRNP footprint extends within the upstream exon far beyond the three conserved nucleotides [85]. Importantly, these ESEs show the same activity in both deletion and non-deletion polymorphism minigenes, indicating that they act independently of the multiple and redundant silencers within the 2,903-nt fragment [31]. From the eight shortlisted ASOs, only ASO-33 partially overlaps with ESE2, while ASO-34-39 targeting ESE2 and ESE3 did show splicing switch, yet without clear upregulation of E4-containing transcripts. In fact, the mechanisms by which a majority of ASOs switch splicing by repressing E3 inclusion but not increasing E4 levels, remain to be elucidated. Last, ASO-28 appears to target a silencer region yet shows clear reduction of E3/E4 levels and increased imatinib-driven cell death, suggesting that the enhancers and silencers cannot be mapped with precision by the deletion scan, and/or that these silencers might act by complex recruitment of both activators and repressors.

An added value of this study is the identification of ESE3 as the sequence that mediates the increase in E3 inclusion by the SRSF1 splicing factor and protooncogene, which was not known before [32]. This result further confirms our identified enhancers and suggests that ESE3 might mediate TKI resistance in tumors with high levels of SRSF1. Despite that our RNA pulldowns are consistent with direct binding of SRSF1 to ESE3, only future in vitro splicing experiments in cell-free extracts might confirm such direct effects, which should reveal further mechanistic insight into this medically relevant alternative splicing event.

The richness of cis-acting elements regulating E3 splicing has been seen in other constitutive and alternative exons $[59,86]$. Indeed, a recent mass-mutational study within an exon revealed that point mutations at $90 \%$ of exonic positions changed the splicing patterns while many combinations of double mutations exhibited nonadditive effects [87]. This study revealed the complex relation between an exonic sequence and its splicing pattern, and strikingly, demonstrated that virtually each exonic nucleotide bears splicing regulatory information. Nevertheless, our combination of systematic deletions and ASO walking mostly confirms the splice-switching action of the ASOs, illustrates that deletion scans can identify functional regions for initial ASO targeting, but that other approaches are required to identify optimal ASOs.

In summary, our study not only expands our knowledge of the regulatory mechanisms for a medically important alternative splicing event, but also reveals a few ASOs as potential adjuvant drugs to overcome TKI resistance in CML and other tyrosine kinase-driven cancers, as well as personalized therapeutics for patients with the BIM deletion polymorphism.

\section{MATERIALS AND METHODS}

\section{Cell lines and chemicals}

We cultured the K562 and KCL22 cell lines in Roswell Park Memorial Institute (RPMI) 1640 Medium (Hyclone) supplemented with penicillin/streptomycin (Gibco) and $10 \%$ fetal bovine serum (Gibco) at $37^{\circ} \mathrm{C}$ with $5 \% \mathrm{CO}_{2}$. We maintained the edited $\mathrm{K} 562-B I M^{\mathrm{i2}+/}$ and K562-BIM ${ }^{\mathrm{I2-}-\mathrm{-}}$ cells [19] in RMPI-1640 medium supplemented with penicillin/streptomycin and 20\% fetal bovine serum. We dissolved imatinib in DMSO at 50\%, stored it at $-20^{\circ} \mathrm{C}$, and used it at $2 \mu \mathrm{M}$ for all experiments unless otherwise indicated. We obtained 2'O-methoxyethyl (MOE) and phosphorothioate ASOs from IONIS Pharmaceuticals (Carlsbad, CA). We dissolved ASOs in nuclease-free $\mathrm{H}_{2} \mathrm{O}$ and kept them at $-20^{\circ} \mathrm{C}$. 


\section{Plasmid construction}

We made mutant plasmids in the context of both $B I M \Delta 10$ and $\Delta 11$ minigenes [31], using PCR mutagenesis with specific primers (sequences available upon request) and KAPA HiFi DNA polymerase (KAPA Biosystems). We generated serial deletions and staggered deletions of 10 nucleotides each in BIM E3 and upstream $106 \mathrm{nt}$ intronic region, by using specific primers which contained the flanking regions of the deleted sequence. We introduced point mutations in enhancer sequences of BIM E3 using specific primers. pCGT7-empty and pCGT7-SRSF1 plasmids were gifted by Prof Javier F Cáceres from MRC Human Genetics Unit at Edinburgh, UK [65].

The pSXN plasmidwas provided by Prof Thomas A Cooper from Baylor College of Medicine, USA [64]. We annealed equimolar amounts of a pair of complementary DNA oligonucleotides containing designed test sequences and restriction overhangs by heating at $95^{\circ} \mathrm{C}$ for 5 min followed by gradual cooling to room temperature for $1 \mathrm{~h}$. We then $5^{\prime}$-end phosphorylated the annealed oligonucleotides by T4 polynucleotide kinase (T4PNK; New England Biolabs) in 1x ligation buffer, and ligated the duplex into the Bam HI and SalI sites in the alternative exon within $\mathrm{pSXN13}$ vector.

\section{Semi-quantitative PCR}

We labeled the 5 '-end of 10 pmol forward primer using 10U T4 PNK (New England Biolabs) and 10.2 pmol $\gamma$-32P-ATP (60 $\mu \mathrm{Ci}$; Perkin Elmer). We then purified the labeled primers by illustra Microspin G-25 column (GE Healthcare Life Sciences) and added them to the primer mixture containing 100 pmol unlabeled reverse primer and 90 pmol unlabeled forward primer. We used cDNA for PCR-amplification using Go-Taq polymerase (Promega) with the radiolabeled primer mixture for 22 cycles. We separated the PCR products by $8 \%(\mathrm{w} / \mathrm{v})$ native polyacrylamide gel, and subsequently exposed the gel's radioactive signals to storage phosphor-imaging screen which was read by Typhoon Trio variable mode imager (GE Healthcare Life Sciences). We analyzed the band intensity with ImageQuant TL software (GE Healthcare Life Sciences). We generated gel images by exposing gels to X-ray films (Kodak) for 12-48 $\mathrm{h}$ in X-ray cassette at $-80^{\circ} \mathrm{C}$ and then processed images by Kodak Model 2000 X-12 ray film processor. The average exon inclusion and standard deviation were derived from the band intensities from at least three experimental replicas. The splicing pattern from endogenous BIM transcripts were normalized to GAPDH. The following primers were used: pSXN_ßglobinEx1-F: 5'-AGGTGAACGTG GATGAAGTTGGTGGTG-3'; pSXN_ßglobinEx2-R: 5'-CGTGCAGCCTTTGACCTAC TAGTGTG-3'; BIME2A-F: 5'-ATGGCAAAGCAACCTTCTGATG-3', BIM-
E3-R: 5'-ATGGTGGTGGCCATACAAAT-3'; BIM-E5-R: 5'-TAACCATTCGTGGGTGGTCT-3'.

\section{Quantitative real-time PCR}

We isolated total RNA from cells using PureLink RNA mini kit and treated it with TURBO DNase (both from Life Technologies). We reverse transcribed $1 \mu \mathrm{g}$ total RNA with M-MuLV reverse transcriptase (New England Biolabs) and oligo-dT. We performed real-time PCR in a $20 \mu \mathrm{l}$ mixture containing $2 \mu \mathrm{l}$ of the five-fold diluted cDNA, $10 \mu \mathrm{l}$ SYBR Select Master Mix (Life Technologies) and $200 \mathrm{nM}$ of each primer in the CFX96 Real-Time PCR System (Bio-Rad) using the following parameters: $95^{\circ} \mathrm{C}$ for $3 \mathrm{~min}, 40$ cycles of $95^{\circ} \mathrm{C}$ for $10 \mathrm{sec}, 58^{\circ} \mathrm{C}$ for $30 \mathrm{sec}$ and $72^{\circ} \mathrm{C}$ for $20 \mathrm{sec}$. We calculated the fluorescence threshold value $(\mathrm{Ct})$ using the thermocycler system software. We ruled out nonspecific products by both the analysis of the melting curves and by electrophoresis in $2 \%$ agarose gels. We normalized endogenous and minigene transcripts to $\beta$-actin or adenovirus exonic sequence (U) transcript levels, respectively. We used the following primers: $\beta$-actin (forward: 5'-CCA GAGGCGTACAGGGATAG-3'; reverse: 5'-CCAACCGCGAGAAGATGA-3'), SRSF1 (forward: 5'-TTCTACAAATACGGCGCTATCC; reverse: 5'-GTACCCATCGTAATCATAGCCG) BIM E2A (forward: 5'-TTCCCCCAAATGTCTGACTC-3'; reverse: 5'-CTTGTGGCTCTGT CTGTAGGG-3'), BIM E3 (forward: 5'-CCAGGCCTTCAACCACTATC-3'; reverse: 5'-ATGGTGGTGGCCATACAAAT-3'), BIM E4 (forward: 5'-TTCCATGAGGCAGGCTG AAC3'; reverse: 5'-CCTCCTTGCATAGTAAGCGTT-3'), U (forward: 5'-CGAGCTCA CTCTCTTCCGC-3'; reverse: 5'-CTGGTAGGGTACCTCGCA-3'), U-E3 (forward: 5'-C GAGCTCACTCTCTTCCGC-3'; reverse: 5'-CTCTAGGATGACTACTGGTAGGGT-3' or U-E3-2 (forward: 5'-CTGCGAGGTACCCTACCAGT-3'; reverse: 5'- GGTGGTGG CCATACAAATCT-3' which were used for detection of E3 levels in D1, SD1, D2 and ESE1 mutants), U-E4 (forward: 5'-CGAGCTCACTCTCTTCCGC-3'; reverse: 5'-CCTCATGGAAGCT GGTAGGGT-3'). Thus, the U-E3, U-E3-2 and U-E4 are junction primers that enhance specificity of amplification. We expressed values as fold change over the corresponding values for the control by the $2^{-\Delta \Delta C t}$ method. Graphs represent the Log 2 of the corresponding real-time RT-PCR values or ratios unless otherwise stated.

\section{Transfection}

We transiently nucleofected $1 \times 10^{6} \mathrm{~K} 562$ or KCL22 cells with $2 \mu \mathrm{M}$ ASO using SF Cell Line Nucleofector kit (Lonza) with program FF-120 and EH-198, respectively. We harvested cells $48 \mathrm{~h}$ after nucleofection. For the samples with Imatinib treatment, we first nucleofected 
cells and after $18 \mathrm{~h}$ added Imatinib, and collected cells $48 \mathrm{~h}$ later.

We transfected K562 cells with minigenes using Xtreme GENE HP transfection reagent (Roche Applied Science) according to the manufacturer's protocol. We incubated the transfected cells at $37^{\circ} \mathrm{C}$ with $5 \% \mathrm{CO}_{2}$ for $48 \mathrm{~h}$ before RNA/protein extraction. For overexpression assay, we mixed minigene plasmids with control pCGT7empty or pCGT7-SRSF1 plasmids at a 1:1 ratio.

\section{Definition of enhancers and silencers from deletion scan}

For each deletion (D) or staggered deletion (SD) in $10 \mathrm{nt}$ segments, the E3/E4 ratio is considered as the average of the mean $\mathrm{E} 3 / \mathrm{E} 4$ ratios from both $\Delta 10$ and $\Delta 11$ minigenes. To derive the final map (Figure 1D), we took the average E3/E4 ratio between each $\mathrm{D}$ and $\mathrm{SD}$ deletion in both $\Delta 10$ and $\Delta 11$ (total of 4 values) and applied it to the $5 \mathrm{nt}$ region where they overlapped. We highlighted each segment as (i) enhancer in blue, (ii) silencer in red, or (iii) neutral as uncolored, based on the following criteria: (i) the $5 \mathrm{nt}$ sequence is part of an ESE/ISE if its E3/E4 average shows a $\geq 30 \%$ decrease compared to WT; (ii) the $5 \mathrm{nt}$ sequence is part of an ESS/ISS if the corresponding average shows a $\geq 30 \%$ compared to WT. For strong ESE/ ISE or ESS/ISS, the cutoff is a $\geq 50 \%$ decrease or increase in the mean $\mathrm{E} 3 / \mathrm{E} 4$ ratio compared to $\mathrm{WT}$, respectively.

\section{RNA pulldown}

We performed RNA pulldown using Pierce Magnetic RNA-Protein Pull-down kit (USA). We incubated 50 pmol synthetic RNA (IDT, USA) with $120 \mu \mathrm{g}$ HeLa nuclear extract. We used the following RNA oligos: (ESE3 WT 5'-UCAACCACAAGGAUUUCUCAUGAUA-3' and ESE3 Mt1 5'-UCAACCAUAAGCAUUUCCCA UGAUA-3'). We separated the pulldown eluates and flow through by $12 \%$ SDS-PAGE, followed by Western Blotting. We performed the pulldown assay in triplicate with consistent results.

\section{Western blotting}

After PBS washing, we resuspended cells in icecold Radioimmunoprecipitation assay (RIPA) lysis buffer (Millipore) supplemented with proteinase inhibitors and phosphatase inhibitors (Roche). We centrifuged cell lysates at $14,000 \mathrm{rpm}$ for $30 \mathrm{~min}$ at $4^{\circ} \mathrm{C}$, and estimated the protein concentrations with the Bradford assay (Bio-Rad). We resolved 10-20 $\mu \mathrm{g}$ of protein samples by $12.5-15 \%$ SDSPAGE gels and then transferred them to PVDF membrane (Bio-Rad). We incubated the blocked membranes with primary and HRP-tagged secondary antibody in 5\% (w/v) nonfat milk and Tris buffered saline-Tween (TBST). Primary antibodies were: anti-SRSF1 (gifted by Prof
Adrian R Krainer from Cold Spring Harbor Laboratory), mouse monoclonal anti-human $\beta$-actin (\#AC-15, Sigma); rabbit polyclonal anti human BIM (\#2819), Caspase-3 (\#9662), Cleaved Caspase-3 (\#9661), PARP (\#9542), phosph-STAT5 (\#9359) and STAT5 (\#9363) antibodies, from Cell Signaling Technology. Secondary antibodies include anti-mouse IgG or anti-rabbit IgG HRP linked antibodies (Santa Cruz). We detected immunostained bands with the enhanced chemiluminescence substrate (Perkin-Elmer) exposed to LAS-4000 imager (Fujifilm).

\section{Viable cell counting}

We counted viable cells through Trypan Blue staining (Sigma-Aldrich) with a haemocytometer (Hausser Scientific), $48 \mathrm{~h}$ after TKI treatment.

\section{ELISA-based DNA fragmentation assay}

Upon harvesting cells at indicated time points, we detected mono- and oligo-nucleosomes in the apoptotic cells using the Cell Death Detection ELISA (SigmaAldrich), according to the manufacturer's instructions.

\section{Cell cycle analysis}

We analyzed the cell cycle kinetics using Apoptosis, DNA damage and Cell Proliferation kit (BD Biosciences). In brief, we treated KCL22 cells with 10 $\mu \mathrm{M}$ Bromodeoxyuridine (BrdU), and after $4 \mathrm{~h}$, we fixed the cells and treated them with DNase according to the manufacturer's instructions. After staining with PerCP$\mathrm{Cy}^{\mathrm{TM}}$ 5.5 Mouse Anti-BrdU and DAPI provided in the kit, we analyzed the cells using LSRFortessa Cell Analyzer (BD Biosciences).

\section{Statistical analysis}

We obtained all the data used for statistics analysis from three independent experiments (different samples from different transfections or treatments). We assessed the difference between groups by the two-tailed Student's t-test using the Microsoft Excel software, with indicated significance at $P \leq 0.05$.

\section{Abbreviations}

5'ss, 5' splice site; 3'ss, 3' splice site; ASO, antisense oligonucleotide; BCL2L11, B-Cell Lymphoma 2-like 11; BIM, BCL-2 interacting mediator of cell death; BIMEL, BIM extra large; BIML, BIM large; BIMS, BIM small; $\mathrm{BIM} \gamma, \mathrm{BIM}$ gamma; bp, base pair; BPS, branch point sequence; BrdU, bromodeoxyuridine; CML, chronic myeloid leukemia; CPSF, Cleavage and Polyadenylation Specificity Factor; E2a, exon 2a; E3, exon 3; E4, exon 4; EGFR, Epidermal growth factor receptor; ESE, exonic splicing enhancer; ESS, exonic splicing silencer; D, 
deletion; hnRNP, heterogeneous nuclear ribonucleoprotein; ISE, intronic splicing enhancer; ISS, intronic splicing silencer; MDS, myelodysplastic syndromes; MOE, 2'-O-methoxyethyl; NSCLC, non-small cell lung cancer; nt, nucleotide; OS, overall survival; PAGE, polyacrylamide gel electrophoresis; PARP, poly (ADP-ribose) polymerase; PFS, progression free survival; PNK, polynucleotide kinase; RIPA, radioimmunoprecipitation assay; RPMI, Roswell Park Memorial Institute; RT-PCR, reversetranscription polymerase chain reaction; $\mathrm{SD}$, staggered deletion; SDS, sodium dodecyl sulfate; snRNP, small nuclear ribonucleoprotein; SR, serine/arginine-rich proteins; SRSF1, serine/arginine-rich splicing factor 1; STAT5, signal transducer and activator of transcription 5; TKI, tyrosine kinase inhibitor; U2AF, U2-auxiliary factor; WT, wild type.

\section{Author contributions}

MB performed the large deletion scan within E3 with help from JL, and WLY performed and analyzed the intronic deletions. MB did the point mutations and other experiments in Figure 2, except the SRSF1 experiment which was mostly done by CWT. JL carried out the majority of the ASO experiments with crucial help from $\mathrm{MB}$ and JRS. XR and STO designed the experiments and analyzed the data with the help of all coauthors. FR designed and supplied the ASOs. XR, JL and STO wrote the manuscript with help from $\mathrm{MB}$, and all other authors read and approved the manuscript.

\section{ACKNOWLEDGMENTS}

We thank all members of the Roca lab for advice.

\section{CONFLICTS OF INTEREST}

FR is a paid employee of Ionis Pharmaceuticals.

\section{GRANT SUPPORT}

We acknowledge funding from the National Medical Research Council of Singapore via a ClinicianScientist Individual Research Grant (CS-IRG) (NMRC/ CIRG/1330/2012) to STO and XR, and a Clinician Scientist Award (NMRC/CSA/0051/2013) to STO, as well as Academic Research Fund Tier 1 grant (RG137/16 (S)) from Singapore's Ministry of Education to XR. The funders had no role in study design, data collection and analysis, decision to publish, or preparation of the manuscript.

\section{REFERENCES}

1. Sequist LV, Martins RG, Spigel D, Grunberg SM, Spira A, Janne PA, Joshi VA, McCollum D, Evans TL, Muzikansky A, Kuhlmann GL, Han M, Goldberg JS, et al. First-line gefitinib in patients with advanced non-small-cell lung cancer harboring somatic EGFR mutations. J Clin Oncol. 2008; 26:2442-2449.

2. Druker BJ. Translation of the Philadelphia chromosome into therapy for CML. Blood. 2008; 112:4808-4817.

3. Mok TS, Wu YL, Thongprasert S, Yang CH, Chu DT, Saijo N, Sunpaweravong P, Han B, Margono B, Ichinose Y, Nishiwaki Y, Ohe Y, Yang JJ, et al. Gefitinib or carboplatinpaclitaxel in pulmonary adenocarcinoma. N Engl J Med. 2009; 361:947-957.

4. Druker BJ, Guilhot F, O'Brien SG, Gathmann I, Kantarjian H, Gattermann N, Deininger MW, Silver RT, Goldman JM, Stone RM, Cervantes F, Hochhaus A, Powell BL, et al. Fiveyear follow-up of patients receiving imatinib for chronic myeloid leukemia. N Engl J Med. 2006; 355:2408-2417.

5. Tsao MS, Sakurada A, Cutz JC, Zhu CQ, Kamel-Reid S, Squire J, Lorimer I, Zhang T, Liu N, Daneshmand M, Marrano P, da Cunha Santos G, Lagarde A, et al. Erlotinib in lung cancer - molecular and clinical predictors of outcome. N Engl J Med. 2005; 353:133-144.

6. Janne PA, Gurubhagavatula S, Yeap BY, Lucca J, Ostler P, Skarin AT, Fidias P, Lynch TJ, Johnson BE. Outcomes of patients with advanced non-small cell lung cancer treated with gefitinib (ZD1839, "Iressa") on an expanded access study. Lung Cancer. 2004; 44:221-230.

7. Linardou H, Dahabreh IJ, Bafaloukos D, Kosmidis P, Murray S. Somatic EGFR mutations and efficacy of tyrosine kinase inhibitors in NSCLC. Nat Rev Clin Oncol. 2009; 6:352-366.

8. Aichberger KJ, Mayerhofer M, Krauth MT, Vales A, Kondo R, Derdak S, Pickl WF, Selzer E, Deininger M, Druker BJ, Sillaber C, Esterbauer H, Valent P. Low-level expression of proapoptotic $\mathrm{Bcl}$-2-interacting mediator in leukemic cells in patients with chronic myeloid leukemia: role of BCR/ABL, characterization of underlying signaling pathways, and reexpression by novel pharmacologic compounds. Cancer Res. 2005; 65:9436-9444.

9. Costa DB, Halmos B, Kumar A, Schumer ST, Huberman MS, Boggon TJ, Tenen DG, Kobayashi S. BIM mediates EGFR tyrosine kinase inhibitor-induced apoptosis in lung cancers with oncogenic EGFR mutations. PLoS Med. 2007; 4:1669-1679.

10. Cragg MS, Kuroda J, Puthalakath H, Huang DC, Strasser A. Gefitinib-induced killing of NSCLC cell lines expressing mutant EGFR requires BIM and can be enhanced by BH3 mimetics. PLoS Med. 2007; 4:1681-1689.

11. Essafi A, Fernandez de Mattos S, Hassen YA, Soeiro I, Mufti GJ, Thomas NS, Medema RH, Lam EW. Direct transcriptional regulation of $\mathrm{Bim}$ by FoxO3a mediates STI571-induced apoptosis in Bcr-Abl-expressing cells. Oncogene. 2005; 24:2317-2329.

12. Kuroda J, Puthalakath H, Cragg MS, Kelly PN, Bouillet P, Huang DC, Kimura S, Ottmann OG, Druker BJ, Villunger A, Roberts AW, Strasser A. Bim and Bad mediate imatinibinduced killing of $\mathrm{Bcr} / \mathrm{Abl}+$ leukemic cells, and resistance 
due to their loss is overcome by a BH3 mimetic. Proc Natl Acad Sci U S A. 2006; 103:14907-14912.

13. Mestre-Escorihuela C, Rubio-Moscardo F, Richter JA, Siebert R, Climent J, Fresquet V, Beltran E, Agirre X, Marugan I, Marin M, Rosenwald A, Sugimoto KJ, Wheat LM, et al. Homozygous deletions localize novel tumor suppressor genes in B-cell lymphomas. Blood. 2007; 109:271-280.

14. Youle RJ, Strasser A. The BCL-2 protein family: opposing activities that mediate cell death. Nat Rev Mol Cell Biol. 2008; 9:47-59.

15. Gazdar AF. Activating and resistance mutations of EGFR in non-small-cell lung cancer: role in clinical response to EGFR tyrosine kinase inhibitors. Oncogene. 2009; 28:S24-31.

16. Sharma SV, Bell DW, Settleman J, Haber DA. Epidermal growth factor receptor mutations in lung cancer. Nat Rev Cancer. 2007; 7:169-181.

17. Sequist LV, Bell DW, Lynch TJ, Haber DA. Molecular predictors of response to epidermal growth factor receptor antagonists in non-small-cell lung cancer. J Clin Oncol. 2007; 25:587-595.

18. Cardona AF, Rojas L, Wills B, Arrieta O, Carranza H, Vargas C, Otero J, Corrales-Rodriguez L, Martin C, Reguart N, Archila P, Rodriguez J, Cuello M, et al. BIM deletion polymorphisms in Hispanic patients with non-small cell lung cancer carriers of EGFR mutations. Oncotarget. 2016; 7:68933-68942. https://doi.org/10.18632/oncotarget.12112.

19. Ng KP, Hillmer AM, Chuah CT, Juan WC, Ko TK, Teo AS, Ariyaratne PN, Takahashi N, Sawada K, Fei Y, Soh $\mathrm{S}$, Lee WH, Huang JW, et al. A common BIM deletion polymorphism mediates intrinsic resistance and inferior responses to tyrosine kinase inhibitors in cancer. Nat Med. 2012; 18:521-528.

20. Soh S, Allen J, Siddiqui FJ, Ong ST, Lim LWT. The BIM deletion polymorphism in East Asian EGFR-mutated nonsmall cell lung cancer: a meta-analysis of primary data. Manuscript in preparation.

21. Isobe K, Hata Y, Tochigi N, Kaburaki K, Kobayashi H, Makino T, Otsuka H, Sato F, Ishida F, Kikuchi N, Hirota N, Sato K, Sano G, et al. Clinical significance of BIM deletion polymorphism in non-small-cell lung cancer with epidermal growth factor receptor mutation. J Thorac Oncol. 2014; 9:483-487.

22. Zhao M, Zhang Y, Cai W, Li J, Zhou F, Cheng N, Ren R, Zhao C, Li X, Ren S, Zhou C, Hirsch FR. The Bim deletion polymorphism clinical profile and its relation with tyrosine kinase inhibitor resistance in Chinese patients with nonsmall cell lung cancer. Cancer. 2014; 120:2299-2307.

23. Lee JH, Lin YL, Hsu WH, Chen HY, Chang YC, Yu CJ, Shih JY, Lin CC, Chen KY, Ho CC, Laio WY, Yang PC, Yang JC. Bcl-2-like protein 11 deletion polymorphism predicts survival in advanced non-small-cell lung cancer. J Thorac Oncol. 2014; 9:1385-1392.
24. Ma JY, Yan HJ, Gu W. Association between BIM deletion polymorphism and clinical outcome of EGFR-mutated NSCLC patient with EGFR-TKI therapy: A meta-analysis. J Cancer Res Ther. 2015; 11:397-402.

25. Nie W, Tao X, Wei H, Chen WS, Li B. The BIM deletion polymorphism is a prognostic biomarker of EGFR-TKIs response in NSCLC: A systematic review and metaanalysis. Oncotarget. 2015; 6:25696-25700. https://doi. org/10.18632/oncotarget.4678.

26. Lee JK, Shin JY, Kim S, Lee S, Park C, Kim JY, Koh Y, Keam B, Min HS, Kim TM, Jeon YK, Kim DW, Chung DH, et al. Primary resistance to epidermal growth factor receptor (EGFR) tyrosine kinase inhibitors (TKIs) in patients with non-small-cell lung cancer harboring TKI-sensitive EGFR mutations: an exploratory study. Ann Oncol. 2013; 24:2080-2087.

27. Lee JY, Ku BM, Lim SH, Lee MY, Kim H, Kim M, Kim S, Jung HA, Sun JM, Ahn JS, Park K, Ahn MJ. The BIM Deletion Polymorphism and its Clinical Implication in Patients with EGFR-Mutant Non-Small-Cell Lung Cancer Treated with EGFR Tyrosine Kinase Inhibitors. J Thorac Oncol. 2015; 10:903-909.

28. Ishikawa $\mathrm{T}$, Toyoda $\mathrm{Y}$, Yoshiura $\mathrm{K}$, Niikawa $\mathrm{N}$. Pharmacogenetics of human $\mathrm{ABC}$ transporter $\mathrm{ABCC} 11$ : new insights into apocrine gland growth and metabolite secretion. Front Genet. 2012; 3:306.

29. Soh SX, Siddiqui FJ, Allen JC, Kim GW, Lee JC, Yatabe Y, Soda M, Mano H, Soo RA, Chin TM, Ebi H, Yano S, Matsuo K, et al. A systematic review and meta-analysis of individual patient data on the impact of the BIM deletion polymorphism on treatment outcomes in epidermal growth factor receptor mutant lung cancer. Oncotarget. 2017; 8:41474-41486. https://doi.org/10.18632/oncotarget.17102.

30. O'Connor L, Strasser A, O'Reilly LA, Hausmann G, Adams JM, Cory S, Huang DC. Bim: a novel member of the Bcl-2 family that promotes apoptosis. EMBO J. 1998; 17:384-395.

31. Juan WC, Roca X, Ong ST. Identification of cis-acting elements and splicing factors involved in the regulation of BIM Pre-mRNA splicing. PLoS One. 2014; 9:e95210.

32. Anczukow O, Rosenberg AZ, Akerman M, Das S, Zhan L, Karni R, Muthuswamy SK, Krainer AR. The splicing factor SRSF1 regulates apoptosis and proliferation to promote mammary epithelial cell transformation. Nat Struct Mol Biol. 2012; 19:220-228.

33. Hara H, Takeda T, Yamamoto N, Furuya K, Hirose K, Kamiya T, Adachi T. Zinc-induced modulation of SRSF6 activity alters Bim splicing to promote generation of the most potent apoptotic isoform BimS. FEBS J. 2013; 280:3313-3327.

34. Kedzierska H, Poplawski P, Hoser G, Rybicka B, Rodzik K, Sokol E, Boguslawska J, Tanski Z, Fogtman A, Koblowska M, Piekielko-Witkowska A. Decreased Expression of SRSF2 Splicing Factor Inhibits Apoptotic Pathways in Renal Cancer. Int J Mol Sci. 2016; 17. 
35. Anczukow O, Krainer AR. Splicing-factor alterations in cancers. RNA. 2016; 22:1285-1301.

36. Nilsen TW, Graveley BR. Expansion of the eukaryotic proteome by alternative splicing. Nature. 2010; 463:457-463.

37. Cooper TA, Wan L, Dreyfuss G. RNA and disease. Cell. 2009; 136:777-793.

38. Sheth N, Roca X, Hastings ML, Roeder T, Krainer AR, Sachidanandam R. Comprehensive splice-site analysis using comparative genomics. Nucleic Acids Res. 2006; 34:3955-3967.

39. Busch A, Hertel KJ. Evolution of SR protein and hnRNP splicing regulatory factors. Wiley Interdiscip Rev RNA. 2012; 3:1-12.

40. Wahl MC, Will CL, Luhrmann R. The spliceosome: design principles of a dynamic RNP machine. Cell. 2009; 136:701-718.

41. Hang J, Wan R, Yan C, Shi Y. Structural basis of pre-mRNA splicing. Science. 2015; 349:1191-1198

42. Yan C, Hang J, Wan R, Huang M, Wong CC, Shi Y. Structure of a yeast spliceosome at 3.6-angstrom resolution. Science. 2015; 349:1182-1191.

43. Anczukow O, Akerman M, Clery A, Wu J, Shen C, Shirole NH, Raimer A, Sun S, Jensen MA, Hua Y, Allain FH, Krainer AR. SRSF1-Regulated Alternative Splicing in Breast Cancer. Mol Cell. 2015; 60:105-117.

44. Karni R, de Stanchina E, Lowe SW, Sinha R, Mu D, Krainer AR. The gene encoding the splicing factor SF2/ASF is a proto-oncogene. Nat Struct Mol Biol. 2007; 14:185-193.

45. Yoshida K, Sanada M, Shiraishi Y, Nowak D, Nagata Y, Yamamoto R, Sato Y, Sato-Otsubo A, Kon A, Nagasaki M, Chalkidis G, Suzuki Y, Shiosaka M, et al. Frequent pathway mutations of splicing machinery in myelodysplasia. Nature. 2011; 478:64-69.

46. Bonnal S, Vigevani L, Valcarcel J. The spliceosome as a target of novel antitumour drugs. Nat Rev Drug Discov. 2012; 11:847-859.

47. Lu ZX, Jiang P, Xing Y. Genetic variation of pre-mRNA alternative splicing in human populations. Wiley Interdiscip Rev RNA. 2012; 3:581-592.

48. Roca X, Olson AJ, Rao AR, Enerly E, Kristensen VN, Borresen-Dale AL, Andresen BS, Krainer AR, Sachidanandam R. Features of 5'-splice-site efficiency derived from disease-causing mutations and comparative genomics. Genome Res. 2008; 18:77-87.

49. Rigo F, Seth PP, Bennett CF. Antisense oligonucleotidebased therapies for diseases caused by pre-mRNA processing defects. Adv Exp Med Biol. 2014; 825:303-352.

50. Aartsma-Rus A. FDA Approval of Nusinersen for Spinal Muscular Atrophy Makes 2016 the Year of Splice Modulating Oligonucleotides. Nucleic Acid Ther. 2017; 27:67-69.

51. Mercatante DR, Bortner CD, Cidlowski JA, Kole R. Modification of alternative splicing of Bcl-x pre-mRNA in prostate and breast cancer cells. analysis of apoptosis and cell death. J Biol Chem. 2001; 276:16411-16417.

52. Taylor JK, Zhang QQ, Wyatt JR, Dean NM. Induction of endogenous Bcl-xS through the control of Bcl-x pre-mRNA splicing by antisense oligonucleotides. Nat Biotechnol. 1999; 17:1097-1100.

53. Wang Z, Jeon HY, Rigo F, Bennett CF, Krainer AR. Manipulation of PK-M mutually exclusive alternative splicing by antisense oligonucleotides. Open Biol. 2012; 2:120133.

54. Zammarchi F, de Stanchina E, Bournazou E, Supakorndej T, Martires K, Riedel E, Corben AD, Bromberg JF, Cartegni L. Antitumorigenic potential of STAT3 alternative splicing modulation. Proc Natl Acad Sci U S A. 2011; 108:17779-17784.

55. Nakagawa T, Takeuchi S, Yamada T, Ebi H, Sano T, Nanjo S, Ishikawa D, Sato M, Hasegawa Y, Sekido Y, Yano S. EGFR-TKI Resistance Due to BIM Polymorphism Can Be Circumvented in Combination with HDAC Inhibition. Cancer Res. 2013.

56. Ko TK, Chin HS, Chuah CT, Huang JW, Ng KP, Khaw SL, Huang DC, Ong ST. The BIM deletion polymorphism: A paradigm of a permissive interaction between germline and acquired TKI resistance factors in chronic myeloid leukemia. Oncotarget. 2016; 7:2721-2733. https://doi. org/10.18632/oncotarget.5436.

57. West AC, Johnstone RW. New and emerging HDAC inhibitors for cancer treatment. J Clin Invest. 2014; 124:30-39.

58. Leverson JD, Phillips DC, Mitten MJ, Boghaert ER, Diaz D, Tahir SK, Belmont LD, Nimmer P, Xiao Y, Ma XM, Lowes KN, Kovar P, Chen J, et al. Exploiting selective BCL-2 family inhibitors to dissect cell survival dependencies and define improved strategies for cancer therapy. Sci Transl Med. 2015; 7:279ra240.

59. Tang SJ, Luo S, Ho JX, Ly PT, Goh E, Roca X. Characterization of the Regulation of CD46 Alternative Splicing. J Biol Chem. 2016.

60. Kyburz A, Friedlein A, Langen H, Keller W. Direct interactions between subunits of CPSF and the U2 snRNP contribute to the coupling of pre-mRNA 3' end processing and splicing. Mol Cell. 2006; 23:195-205.

61. Millevoi S, Loulergue C, Dettwiler S, Karaa SZ, Keller $\mathrm{W}$, Antoniou M, Vagner S. An interaction between U2AF 65 and $\mathrm{CF} \mathrm{I}(\mathrm{m})$ links the splicing and $3^{\prime}$ end processing machineries. EMBO J. 2006; 25:4854-4864.

62. Niwa M, Berget SM. Mutation of the AAUAAA polyadenylation signal depresses in vitro splicing of proximal but not distal introns. Genes Dev. 1991; 5:2086-2095.

63. Desmet FO, Hamroun D, Lalande M, Collod-Beroud G, Claustres M, Beroud C. Human Splicing Finder: an online bioinformatics tool to predict splicing signals. Nucleic Acids Res. 2009; 37:e67. 
64. Coulter LR, Landree MA, Cooper TA. Identification of a new class of exonic splicing enhancers by in vivo selection. Mol Cell Biol. 1997; 17:2143-2150.

65. Cazalla D, Zhu J, Manche L, Huber E, Krainer AR, Caceres JF. Nuclear export and retention signals in the RS domain of SR proteins. Mol Cell Biol. 2002; 22:6871-6882.

66. Melo JV, Chuah C. Novel agents in CML therapy: tyrosine kinase inhibitors and beyond. Hematology Am Soc Hematol Educ Program. 2008:427-435.

67. Savage DG, Antman KH. Imatinib mesylate--a new oral targeted therapy. N Engl J Med. 2002; 346:683-693.

68. Kuribara R, Honda H, Matsui H, Shinjyo T, Inukai T, Sugita $\mathrm{K}$, Nakazawa $\mathrm{S}$, Hirai H, Ozawa $\mathrm{K}$, Inaba T. Roles of Bim in apoptosis of normal and Bcr-Abl-expressing hematopoietic progenitors. Mol Cell Biol. 2004; 24:6172-6183.

69. Deininger MW, Goldman JM, Lydon N, Melo JV. The tyrosine kinase inhibitor CGP57148B selectively inhibits the growth of BCR-ABL-positive cells. Blood. 1997; 90:3691-3698.

70. Ly C, Arechiga AF, Melo JV, Walsh CM, Ong ST. BcrAbl kinase modulates the translation regulators ribosomal protein S6 and 4E-BP1 in chronic myelogenous leukemia cells via the mammalian target of rapamycin. Cancer Res. 2003; 63:5716-5722.

71. Mahon FX, Deininger MW, Schultheis B, Chabrol J, Reiffers J, Goldman JM, Melo JV. Selection and characterization of BCR-ABL positive cell lines with differential sensitivity to the tyrosine kinase inhibitor STI571: diverse mechanisms of resistance. Blood. 2000; 96:1070-1079.

72. Shah NP, Kasap C, Weier C, Balbas M, Nicoll JM, Bleickardt E, Nicaise C, Sawyers CL. Transient potent BCR-ABL inhibition is sufficient to commit chronic myeloid leukemia cells irreversibly to apoptosis. Cancer Cell. 2008; 14:485-493.

73. Fang G, Kim CN, Perkins CL, Ramadevi N, Winton E, Wittmann S, Bhalla KN. CGP57148B (STI-571) induces differentiation and apoptosis and sensitizes Bcr-Abl-positive human leukemia cells to apoptosis due to antileukemic drugs. Blood. 2000; 96:2246-2253.

74. Hua Y, Vickers TA, Okunola HL, Bennett CF, Krainer AR. Antisense masking of an hnRNP A1/A2 intronic splicing silencer corrects SMN2 splicing in transgenic mice. Am J Hum Genet. 2008; 82:834-848.

75. Nakagawa T, Takeuchi S, Yamada T, Ebi H, Sano T, Nanjo S, Ishikawa D, Sato M, Hasegawa Y, Sekido Y, Yano S. EGFR-TKI resistance due to BIM polymorphism can be circumvented in combination with HDAC inhibition. Cancer Res. 2013; 73:2428-2434.

76. Rauzan M, Chuah CT, Ko TK, Ong ST. The HDAC inhibitor SB939 overcomes resistance to BCR-ABL kinase
Inhibitors conferred by the BIM deletion polymorphism in chronic myeloid leukemia. PLoS One. 2017; 12:e0174107.

77. Tanimoto A, Takeuchi S, Arai S, Fukuda K, Yamada T, Roca X, Ong ST, Yano S. Histone Deacetylase 3 Inhibition Overcomes BIM Deletion Polymorphism-Mediated Osimertinib Resistance in EGFR-Mutant Lung Cancer. Clin Cancer Res. 2017; 23:3139-3149.

78. Koschmieder S, Gottgens B, Zhang P, Iwasaki-Arai J, Akashi K, Kutok JL, Dayaram T, Geary K, Green AR, Tenen DG, Huettner CS. Inducible chronic phase of myeloid leukemia with expansion of hematopoietic stem cells in a transgenic model of BCR-ABL leukemogenesis. Blood. 2005; 105:324-334.

79. Hua Y, Sahashi K, Hung G, Rigo F, Passini MA, Bennett CF, Krainer AR. Antisense correction of SMN2 splicing in the CNS rescues necrosis in a type III SMA mouse model. Genes Dev. 2010; 24:1634-1644.

80. Hua Y, Sahashi K, Rigo F, Hung G, Horev G, Bennett CF, Krainer AR. Peripheral SMN restoration is essential for long-term rescue of a severe spinal muscular atrophy mouse model. Nature. 2011; 478:123-126.

81. Depreux FF, Wang L, Jiang H, Jodelka FM, Rosencrans RF, Rigo F, Lentz JJ, Brigande JV, Hastings ML. Antisense oligonucleotides delivered to the amniotic cavity in utero modulate gene expression in the postnatal mouse. Nucleic Acids Res. 2016.

82. Chan SL, Huppertz I, Yao C, Weng L, Moresco JJ, Yates JR 3rd, Ule J, Manley JL, Shi Y. CPSF30 and Wdr33 directly bind to AAUAAA in mammalian mRNA 3' processing. Genes Dev. 2014; 28:2370-2380.

83. Rigo F, Kazerouninia A, Nag A, Martinson HG. The RNA tether from the poly(A) signal to the polymerase mediates coupling of transcription to cleavage and polyadenylation. Mol Cell. 2005; 20:733-745.

84. Rigo F, Martinson HG. Functional coupling of last-intron splicing and 3 '-end processing to transcription in vitro: the poly(A) signal couples to splicing before committing to cleavage. Mol Cell Biol. 2008; 28:849-862.

85. Yu Y, Maroney PA, Denker JA, Zhang XH, Dybkov O, Luhrmann R, Jankowsky E, Chasin LA, Nilsen TW. Dynamic regulation of alternative splicing by silencers that modulate $5^{\prime}$ splice site competition. Cell. 2008; 135:1224-1236.

86. Schaal TD, Maniatis T. Multiple distinct splicing enhancers in the protein-coding sequences of a constitutively spliced pre-mRNA. Mol Cell Biol. 1999; 19:261-273.

87. Julien P, Minana B, Baeza-Centurion P, Valcarcel J, Lehner B. The complete local genotype-phenotype landscape for the alternative splicing of a human exon. Nat Commun. 2016; 7:11558. 